\title{
QUALITATIVE AND QUANTITATIVE ASSESSMENT OF INTERIOR MOISTURE BUFFERING BY ENCLOSURES
}

\author{
HANS JANSSEN ${ }^{1}$ AND STAF ROELS ${ }^{2}$ \\ ${ }^{1}$ Departement of Civil Engineering, Technical University of Denmark \\ Brovej - Building 118, 2800 Kgs. Lyngby, Denmark \\ ${ }^{2}$ Laboratory of Building Physics, Catholic University of Leuven \\ Kasteelpark Arenberg 40, B-3001 Leuven, Belgium
}

\begin{abstract}
The significance of interior humidity in attaining sustainable, durable, healthy and comfortable buildings is increasingly recognised. Given their significant interaction, interior humidity appraisals need a qualitative and/or quantitative assessment of interior moisture buffering. While the effective moisture penetration depth and effective capacitance models allow quantified assessment, their reliance on the 'moisture penetration depth' necessitates comprehensive material properties and hampers their application to multidimensional interior objects. On the other hand, while various recently suggested protocols for the simple and fast measurement of the moisture buffer potential of interior elements allow qualitative assessment, none of these are currently dependable for a wide range of moisture production regimes.

In response to these flaws, this paper introduces the production-adaptive characterisation of the moisture buffer potential of interior elements and corroborates their superposition toward a room-enclosure moisture buffer potential. It is verified that this enables qualitative comparison of enclosures in relation to interior moisture buffering. It is moreover demonstrated that it forms an alternative basis for quantitative evaluation of interior moisture buffering by the effective moisture penetration depth and effective capacitance models. The presented methodology uses simple and fast measurements only and can also be applied to multimaterial and/or multidimensional interior elements.
\end{abstract}

\section{KEYWORDS}

moisture buffering, moisture buffer potential, moisture buffer value, hygric inertia

\section{INTRODUCTION}

The influences of interior humidity on the performance of building zones, building parts and building occupants are strongly multifaceted and highly interrelated. Interior humidity significantly affects the energy performance of building zones, via the latent cooling loads [1] and the ventilation heating loads [2]. Interior humidity moreover considerably affects the appearance and stability of building parts, via the biological activities of fungi [3] and moulds [4]. Finally, interior humidity substantially affects the health [5,6] and comfort $[7,8]$ of building occupants. The development of sustainable, durable, healthy and comfortable buildings hence requires the assessment of interior humidities.

Those interior humidities are governed by interior moisture sources, moisture transport by ventilation air and moisture exchange with the room enclosure. The latter occurs in all enclosure elements, both interior finishes and interior objects (furniture, carpets, dra-

\footnotetext{
${ }^{1}$ Author to whom correspondence should be addressed

Hans Janssen, Technical University of Denmark, Department of Civil Engineering, Brovej building 118, 2800 Kgs. Lyngby, Denmark, tel.: +45 4525 1861, Fax: +45 4588 3282, email: haj@byg.dtu.dk
} 
pes, books, etc). Several authors stress the importance of such interior moisture buffering in the global interior humidity evolution, supported by measurements [9-12] and simulations [12-16]. Interior moisture buffering is indeed shown to positively affect energy consumption, component durability, thermal comfort and air quality $[10,12,15,17,18]$. The development of sustainable, durable, healthy and comfortable buildings hence requires the quantitative and/or qualitative assessment of interior moisture buffering. Qualitative assessment of interior moisture buffering requires a dependable, single-valued characterisation of the moisture buffer potential (MBP) of room enclosures, allowing comparison of different enclosure designs. Recently various protocols to characterise the MBP of single elements have been suggested [19-22] and their possible superposition to the enclosure level has been proposed as well [23]. This paper demonstrates though that only one of these single-element MBP protocols shows potential. In its current form however, it does not dependably characterise the single-element MBP for the wide variety of practical moisture production schemes. Moreover, its superposition to a room-enclosure MBP remains uncorroborated. The selection of the proper singleelement MBP characterisation protocol, its enhancement to a production-adaptive single-element MBP and the corroboration of its superposition to a room-enclosure MBP form the first goal of this paper.

Quantitative assessment of interior moisture buffering requires simulation of the interior humidity, including the moisture exchange with interior elements. Such simulations are very complicated however: while currently being applied for single rooms with simple finishes $[16,24,25,26,27]$, full simulation of the moisture storage and transport in interior elements remains unrealistic. This would require a detailed knowledge of the geometry and the material properties of all indoor elements - info that is often unavailable -, and it would lead to unacceptable calculation times. Simplified methods are commonly preferred, with the 'effective moisture penetration depth' and 'effective capacitance' models as most common approaches. This paper demonstrates however that their reliance on the 'moisture penetration depth' concept currently implies the time-consuming determination of moisture capacities and permeabilities of all materials involved, and hampers its application to multimaterial and/or multidimensional elements. Establishing that the presented production-adaptive room-enclosure MBP - simple and fast to measure and applicable to both finishes and objects - can be employed to quantify interior moisture buffering forms the second goal of this paper.

An introductory section reiterates the general moisture balance equations for a building zone and its enclosure, and the descriptions of the simplifying 'effective moisture penetration depth' and 'effective capacitance' models, with emphasis on their principal flaws. The second and third sections focus on the qualitative and quantitative assessments of moisture buffering: the dependable characterisation of single-element and room-enclosure MBP and its employment for quantification purposes. A practical example, exemplifying the developed approach, concludes the paper.

\section{MOISTURE BALANCES FOR ROOM AIR AND ENCLOSURE}

In order to predict the evolution of vapour pressure, vapour concentration or dew point, the moisture balance equation for the room air needs to be solved. In combination with thermal information, the interior humidity evolution then can be evaluated, the possibility of surface condensation tested, the HVAC-system optimised, ... Most building energy and hygrothermal models presume the room air well mixed, such that air temperature, humidity and pressure are equal over the entire building zone [28]. Assuming such ideal convective mixing and no surface condensation, supposing air exchange with the exterior environment only, and neglecting the temperature dependency of the air density, the moisture balance for the room air can be written as: 


$$
\frac{V}{R_{v} T_{i}} \cdot \frac{\partial p_{v i}}{\partial t}=\left(p_{v e}-p_{v i}\right) \frac{n V}{3600 R_{v} T_{i}}+G_{v p}-G_{b u f}
$$

with $V /\left(R_{V} T_{i}\right)\left(\mathrm{m}^{3} . \mathrm{kg} / \mathrm{J}\right)$ the moisture capacity of the zone air, $p_{\text {vi/e }}(\mathrm{Pa})$ the partial vapour pressure of interior/exterior air, $n(1 / \mathrm{h})$ the air change rate per hour, $V$ the volume of the zone $\left(\mathrm{m}^{3}\right), R_{v}(462 \mathrm{~J} / \mathrm{kg} / \mathrm{K})$ the gas constant of water vapour, $T_{i}(\mathrm{~K})$ the interior air temperature, $G_{v p}(\mathrm{~kg} / \mathrm{s})$ the interior vapour production and $G_{b u f}(\mathrm{~kg} / \mathrm{s})$ the moisture exchange between room air and room enclosure. The latter is governed by the vapour diffusion in the thin stagnant air layers near the surfaces of the elements, and can be written as:

$$
\mathrm{G}_{\text {buf }}=\sum_{\mathrm{k}} \beta_{\mathrm{k}} \cdot \mathrm{A}_{\mathrm{k}} \cdot\left(\mathrm{p}_{\mathrm{vi}}-\mathrm{p}_{\mathrm{vs}, \mathrm{k}}\right)
$$

with $\beta_{k}(\mathrm{~s} / \mathrm{m})$ the convective surface film coefficient for vapour transfer, $A_{k}\left(\mathrm{~m}^{2}\right)$ the surface area and $p_{v s, k}(\mathrm{~Pa})$ the surface vapour pressure for interior element $k$. The mass storage and transport in each element $k$ is described by:

$$
\frac{\partial w_{k}}{\partial t}=\frac{\xi_{k}}{p_{v, s a t}} \cdot \frac{\partial p_{v, k}}{\partial t}=\nabla\left(\delta_{k}\left(p_{v, k}\right) \nabla p_{v, k}\right)
$$

with $w_{k}\left(\mathrm{~kg} / \mathrm{m}^{3}\right)$ the moisture content, $\xi_{k}\left(\mathrm{~kg} / \mathrm{m}^{3}\right)$ the moisture capacity with respect to relative humidity, $p_{v, \text { sat }}(\mathrm{Pa})$ the saturated vapour pressure and $\delta_{\mathrm{k}}(\mathrm{s})$ the water vapour permeability of the absorbing material $k$.

Thus, analysing the interior humidity evolution in a building zone requires simultaneous solution of Eq. (1) for the room air and Eq. (2-3) for each interior element. Note moreover that Eq. (3) is non-linear: vapour permeability $\delta_{k}$ and moisture capacity $\xi_{k}$ are highly dependent on humidity. Solving the system of equations can only be performed numerically consequently: while being applied for simple cases [16,24,25,26,27], general application remains hardy. The complexity of numerical simulation with multiple, multimaterial and/or multidimensional interior elements yields a far too high computational load. Moreover, the material properties needed similarly lead to a too high experimental load. The moisture exchange between room air and room enclosure is hence commonly simplified, for which two models prevail.

\section{Effective moisture penetration depth and effective capacitance models}

The first model is best known as the 'effective moisture penetration depth' (EMPD) model $[28,29]$. Its key assumption is that only a thin surface layer of the interior element's material contributes to the moisture buffering process. Moisture storage and transport in this buffer layer is described with a single control-volume equation. For a single buffer layer with available exchange surface $A\left(\mathrm{~m}^{2}\right)$, Eq. (2-3) combine to:

$$
\mathrm{G}_{\mathrm{buf}}=\mathrm{A} \cdot \frac{\mathrm{p}_{\mathrm{vi}}-\mathrm{p}_{\mathrm{vb}}}{\frac{1}{\beta}+\frac{\mathrm{d}_{\mathrm{b}}}{2 \cdot \delta_{\mathrm{p}}}}=\mathrm{A} \cdot \xi \cdot \mathrm{d}_{\mathrm{b}} \frac{\partial}{\partial \mathrm{t}}\left(\frac{\mathrm{p}_{\mathrm{vb}}}{\mathrm{p}_{\mathrm{v}, \mathrm{sat}}\left(\theta_{\mathrm{b}}\right)}\right)
$$

where $p_{v b}(\mathrm{~Pa})$ and $\theta_{b}\left({ }^{\circ} \mathrm{C}\right)$ are the representative vapour pressure and temperature in the buffer layer with thickness $d_{b}(\mathrm{~m})$ and $\delta_{\mathrm{p}}(\mathrm{s})$ and $\xi\left(\mathrm{kg} / \mathrm{m}^{3}\right)$ are the water vapour permeability and moisture capacity of the buffering layer. The thickness $d_{b}$ of the buffering layer is related to the effective moisture penetration depth $d_{p}(\mathrm{~m})$ which in turn depends on the period of the humidity variations in the room:

$$
d_{b}=a \cdot d_{p}=a \cdot \sqrt{\frac{t_{p} \cdot \delta \cdot p_{v, s a t}\left(\theta_{b}\right)}{\pi \cdot \xi}} \quad a=\min \left(d / d_{p}, 1\right)
$$


where $t_{p}(\mathrm{~s})$ is the period and a (-) an adjustment factor accounting for the fact that the actual thickness $d(\mathrm{~m})$ of the material may be below the effective moisture penetration depth $d_{p}$. Hence, simplifying the humidity buffer layer to one buffer layer with thickness $d_{b}$ only yields reliable results for cyclic humidity variations with a constant period $t_{p}$. To overcome this problem, more advanced models make use of surface and deep storage layers. In this way, both short- and long-term exchanges can be modelled.

The main disadvantage of the EMPD model is its reliance on the moisture penetration depth of the material. Until now this property can only be calculated from the moisture capacity and vapour permeability, measurements which are time and labour intensive. Furthermore, the calculation of the moisture penetration depth is not well-defined for interior finishes with multiple finite-thickness material layers. The most important limitation though is that it is primarily developed for interior finishes (one-dimensional building walls), while only with great difficulty applicable to interior objects (carpets, drapes, furnishing or other multidimensional objects), which most often form the main buffer capacity of a room enclosure. The EMPD method moreover necessitates solution of Eq. (4) for each interior element, swiftly increasing the computational load when realistic enclosures are considered. Finally, while allowing quantification, the EMPD model does not support qualitative assessment of the room-enclosure MBP. The surface areas, buffer thicknesses, vapour permeabilities and moisture capacities of the different elements in the enclosure cannot be easily superposed to one simple enclosure MBP.

In the second method, often named 'effective capacitance' model (EC model), it is presumed that the humidity in the active part of the room enclosure is at all times in equilibrium with the room air humidity [30]. The moisture buffering capacity of the room enclosure can then easily be added to the room air capacity, reducing Eq. (1) to:

$$
M \cdot \frac{V}{R_{v} T_{i}} \cdot \frac{\partial p_{v i}}{\partial t}=\left(p_{v e}-p_{v i}\right) \frac{n V}{3600 R_{v} T_{i}}+G_{v p}
$$

where $M(-)$ is the multiplication factor for the room air moisture capacity. Such renders the effective capacitance model a very easy method, since no extra equations are to be solved. Furthermore the multiplication factor $\mathrm{M}$ could also qualitatively characterise the room-enclosure MBP: a larger M implies a larger potential for moisture buffering.

The correction factor $M$ however remains very vaguely defined. Often only rough minimum and maximum values are given [e.g. 30,31]. Alternatively, M could be calculated from the surface area, moisture capacity and moisture penetration depth of the interior element:

$$
M \cdot \frac{V}{R_{v} T_{i}} \cdot=\left(\frac{V}{R_{v} T_{i}}+\frac{\text { A.p. } \xi \cdot d_{b}}{p_{v, s a t}\left(\theta_{i}\right)}\right)
$$

In that case though, some of the drawbacks mentioned for the EMPD model also enter here. Additionally, this definition of $\mathrm{M}$ can not be considered a reliable characterisation of the room-enclosure MBP: it centres on the moisture capacity only, while omitting any consideration of the moisture permeabilities involved.

It is obvious that the current possibilities for the qualitative and quantitative assessment of interior moisture buffering are not optimal. In the next section we will introduce a dependable characterisation of single-element and room-enclosure MBP based on simple and fast measurements only. The ensuing section will establish that such MBP characterisation can be equally employed for quantification purposes.

\section{CHARACTERISATION OF SINGLE-ELEMENT AND ROOM-ENCLOSURE MBP}

The hygric interactions between the room air and enclosure are determined by the contributions of the different elements comprised in the enclosure: the interior finishes and 
the interior objects - furniture, carpets, drapes, books etc. To dependably characterise the MBP of enclosures, a characterisation of the MBP of single elements is hence needed first. First and foremost any single-element MBP characterisation has to dependably assess the potential of the element to absorb and/or release moisture, in response to variously timed humidity variations in the ambient atmosphere. As such, the singleelement MBP characterisation has to aim at the finite surface mass transfer coefficient controlled response of real elements, with (multiple) finite thickness (materials) or multidimensional features. Moreover the single-element MBP characterisation should yield a limited set of values, allowing for a direct qualitative comparison of different elements. Finally the single-element MBP characterisation should ideally only involve simple and fast measurement techniques and equipment. This leads to three criteria for the singleelement MBP characterisation:

1. dependable assessment of the element's MBP (dependability);

2. direct qualitative comparison of different elements (comparison);

3. characterisation with simple and fast methods (measurement);

Moreover, straightforward extension to the room enclosure level for both qualitative and quantitative purposes should be possible, defining two additional criteria:

4. extendibility to the level of the room enclosure (extendibility);

5. quantification of moisture buffer performance (quantification);

These criteria form the basis for the selection and elaboration of a sound procedure for the characterisation of single-element and room-enclosure MBP. For reasons of conciseness, this paper mostly focuses on homogeneous single-layer interior finishes. The developed methodology does however similarly apply to more complex interior finishes and to interior objects. Any 'interior element' in this article thus refers to an 'interior finish', but implies the analogous approach for an 'interior object'.

\section{Single-element MBP characterisation protocol}

\section{Proposals for single-element MBP characterisation}

Recently numerous proposals for the MBP characterisation of single finishing materials and finishes have been presented, besides the common moisture capacity and permeability. The moisture effusivity was suggested as "theoretical description" of the singleelement MBP by Rode et al. [19]. Delgado et al. [20] advocate the use of sorption kinetics: the moisture accumulation in a sample of the element due to a single step-change in ambient relative humidity $(\mathrm{RH})$ is curve-fitted with a predefined formula, involving an equivalent element storage and transport parameter. Japanese Industrial Standard $A$ 1470-1 [21], Draft International Standard 24353 [22], and the Nordtest Moisture Buffer Value protocol [19] propose using the amplitude of the moisture accumulation in a element sample exposed to cyclic step changes in ambient $\mathrm{RH}$.

While the standard moisture capacity and moisture permeability allow calculation of the hygric response of materials, they are as such not a valid single-element MBP characterisation. As material properties, they do not represent variously timed humidity variations, finite surface mass transfer coefficients, (multiple) finite thickness (materials) nor multidimensional features. In addition, they do not allow direct comparison of different elements, due to the coupled relation with the MBP: materials with a high capacity and average permeability may have a similar MBP's as materials with an average capacity and high permeability.

The effusivity, the proportionality that appears in the relation between the moisture accumulation in a half-infinite homogeneous slab due to a surface vapour pressure change and the square root of time, does not suffer from this and thus results in a comparable characterisation of the MBP. Again though, being a material property, the effusivity 
can not account for variously timed humidity variations, finite surface mass transfer coefficients, (multiple) finite thickness (materials) or multidimensional features.

The application of sorption kinetics to step-change (de)sorption experiments allows arriving at whole-element storage and transport parameters thus accounting for variously timed humidity variations, finite surface mass transfer coefficients, (multiple) finite thickness (materials) and multidimensional features. The double description with a storage and transport parameter gives issues similar to the moisture capacity and permeability though: the direct comparison of different elements is difficult.

Most attention has hence gone to MBP characterisations from cyclic step-change (de)sorption measurements $[19,21,22]$. The sample of the element is conditioned to a specific $\mathrm{RH}$, and sealed at all but its normally exposed sides. It is then alternatingly exposed to a high and low ambient humidity for predefined intervals of time. The sample's moisture mass evolution is recorded and the MBP is obtained from the normalised amplitude of this signal. Its measurement is simple and fast. Yielding a single value, the procedure allows a direct qualitative comparison of different elements. Accounting for finite surface mass transfer coefficients, (multiple) finite thickness (materials) and multidimensional features, these protocols form a good foundation for the dependable characterisation of the MBP of interior elements. It will be shown below though that such dependability requires an extension of the current protocols. Before we do so, the differences between the procedures, and their consequences for MBP characterisation, will be highlighted.

\section{Cyclic step-change (de)sorption measurements}

The Japanese Industrial Standard (JIS), Draft International Sta8ndard (DIS) and Nordtest protocol (NT) formulate similar procedures, making use of cyclic step-change (de)sorption measurements. NT defines the 'Moisture Buffer Value' (MBV) of a finish by a normalisation of the moisture mass amplitude per $\mathrm{m}^{2}$ and \% $\mathrm{RH}$ change:

$$
\mathrm{MBV}_{8 \mathrm{~h}}=\frac{\mathrm{m}_{\text {max }}-\mathrm{m}_{\text {min }}}{\mathrm{A} \cdot\left(\varphi_{\text {high }}-\varphi_{\text {low }}\right)} \quad\left(\mathrm{kg} /\left(\mathrm{m}^{2} \cdot \% \mathrm{RH}\right)\right)
$$

where $m_{\max / \min }\left(\mathrm{kg} / \mathrm{m}^{2}\right)$ are the maximum/minimum moisture mass of the finish sample, $A\left(m^{2}\right)$ is the exposed surface of the sample, and $\varphi_{\text {high/low }}(-)$ are the high/low RH levels applied in the measurement. An analogous definition for an object is:

$$
\mathrm{MBV}_{8 \mathrm{~h}}{ }^{\prime}=\frac{\mathrm{m}_{\text {max }}-\mathrm{m}_{\text {min }}}{\varphi_{\text {high }}-\varphi_{\text {low }}} \quad(\mathrm{kg} / \% \mathrm{RH})
$$

Illustratively, Figure 1 depicts MBV/MBV' measurements of $1 \mathrm{~m}^{2}$ of cork-board (4 mm), $1 \mathrm{~m}^{2}$ of woollen carpet and a 1 meter long wooden bookshelf with books [32]. The important influence of the latter can be easily observed: to obtain a similar buffer potential as one meter of book shelf, more than $12 \mathrm{~m}^{2}$ of cork-board is needed. Such interior objects are unfortunately difficult to integrate in the current formulations of the EMPD and EC models, which mostly characterise building enclosures by the finishes only.

While all three protocols intend to characterise the MBP of interior finishes (or objects), their procedures differ significantly concerning the $\mathrm{RH}$ levels, the time intervals, the surface mass transfer coefficients and the sample thicknesses involved, as confirmed with Table 1. Moreover, while NT targets the stable final cycle, with fairly equal amounts of sorbed and desorbed moisture, JIS and DIS impose a single or a limited number of cycles and thus allow for differences between sorption and desorption. It is not clear how these should be interpreted or applied though, and therefore, only steady-periodic MBP characterisations are considered here.

Table 1 reveals another fundamental difference between NT and JIS \& DIS: NT's option for a sufficiently thick sample with a sufficiently high surface mass transfer coeffici-

ent reveals that NT essentially desires determining a material property, not accounting 
for finite surface mass transfer coefficients, (multiple) finite thickness (layers) or multidimensional features. This NT choice furthermore assumes that the penetration thickness of the material is known, which may necessitate the full determination of the material's moisture storage and transport properties.

Table 1 indicates that different RH levels, time intervals, surface mass transfer coefficients and sample thicknesses are prescribed by the different protocols. In a sensitivity study [32-34] it has been shown that all these have a significant effect on the resulting MBP-value, and that all should be chosen to closely mimic the real conditions that the interior element would be exposed to. Janssen and Roels [34] conclude that for a dependable single-element MBP characterisation, measurements should be made with:

o $\mathrm{RH}$ levels in accordance with the expected ambient $\mathrm{RH}$;

o samples with build-up and dimensions similar to practice;

o surface mass transfer coefficients as anticipated in practice;

0 time intervals in agreement with the likely moisture production;

\section{Dependability of the MBP characterisation}

Given the probable variability of practical moisture production schemes, particularly the latter statement presents a problem. The current formulation of the MBV protocol is indeed reliable only for a limited set of moisture production schemes. The following paragraphs will present an enhancement to overcome that flaw.

\section{Moisture production regimes in dwellings}

Between 2002 and 2005 a huge measurement campaign was performed to assess the indoor humidity classes in typical Belgium dwellings [35]. The measurement campaign was part of a global research program investigating moisture problems in roof constructions. In total 39 Belgian dwellings were examined: in each dwelling temperatures and relative humidities were logged every 10 minutes. Since previous measurements had indicated that the temperature and relative humidity could vary significantly from room to room, different rooms were measured simultaneously. As example, Figure 2 shows the evolution of the measured RH's in a detached house (social housing without balanced ventilation system, Nieuwpoort, Belgium) over a three day period in February 2004. Based on these measurements, the dwelling corresponds to a moderate indoor climate class [36].

Analysing the evolution of the RH's as measured in the different rooms, it can be seen that the main bedroom agrees rather well with NT's 8 / $16 \mathrm{~h}$ loading/unloading scheme. In the bathroom, living room and kitchen, on the other hand, the loading schemes are much more variable. In the bathroom typical short-term moisture peaks are observed, while the kitchen and living room show moisture production intervals with lengths varying from one to five hours. Similarly variable moisture production schemes are found for non-residential buildings, like offices, museums or schools. For that reason, three different moisture production regimes - long, short, peak - are defined in the next section for the analysis of the moisture buffering in building zones. Conclusively Figure 2 also indicates that the influences of the exterior climate on the interior humidity are small: the key variations are caused by interior moisture production events.

\section{Single-element MBP and interior moisture buffering simulations}

The single-element MBP characterisation by cyclic step-change (de)sorption measurements can only be considered dependable if it yields a reliable measure for the expected effect of the moisture storage in the interior element on the interior humidity variations. More particularly, the dampening of the interior $\mathrm{RH}$ variations by storage in the interior element should be proportional to its MBV. To verify that dependability, the MBV of 15 different finishes and the humidity variations in a room cladded with those are de- 
termined numerically. Notwithstanding the recent proposals of several MBP protocols, their reliability has never been analysed. It will be demonstrated here that the retained cyclic step-change (de)sorption protocol, in its original formulation, does not satisfy this requirement, and that an enhancement is due.

The interior elements studied in this paper have been limited to single-layer homogeneous finishes only, using 7 different building materials at thicknesses of $1 \mathrm{~cm}$ and $10 \mathrm{~cm}$ : wood fibreboard [37], plywood [37], gypsum plaster [38], aerated cellular concrete [39], cellulose insulation [39], flax insulation [39] and perlite insulation [39]. Whereas some of those finishes might in reality never be applied in this way, they are selected for their differing sorption isotherm, water vapour permeability and penetration depth, such that different dynamic responses can be expected. It is reasoned that the resulting range of interior finishes can be considered representative for the moisture buffering by a broad variety of real interior finishes and objects. Note that in this analysis hysteresis on the sorption isotherm is not considered critical and is thus not taken into account. More details on the material data can be found in appendix 1 .

All simulations are performed with a numerical model for moisture transport in building parts [40], which makes use of a finite-element spatial discretisation and a fully implicit temporal discretisation. Use of hygrothermal simulation models for quantifying singleelement MBP and interior moisture buffering has recently been validated $[41,42]$. All simulations are entirely isothermal, with temperatures constant at $20^{\circ} \mathrm{C}$. While such isothermality may be considered a limitation, it is in line with the current practice of the isothermal measurement of moisture capacities, vapour permeabilities - for use in EMPD and EC models - and moisture buffer values. Any deficiency of the EMPD and EC model for non-isothermal conditions will thus not be solved by the current approach: this is however not the aim of this paper.

For the single-element MBP determination, the surface mass transfer coefficient governed response of the material to a rectangular-wave variation in ambient relative humidity is calculated with Eq. (2,3). The Nordtest's 33-75 \% RH levels and 8-16 h time intervals are used in combination with the JIS' real thickness and $2.0 \cdot 10^{-8} \mathrm{~s} / \mathrm{m}$ surface mass transfer coefficient. Simulations are executed for 10 days: a sufficiently steady-periodic cycle is attained after such interval.

For the interior moisture buffering calculation, the humidity variations in a room finished with one of the 15 finishes considered are simulated with Eq. (1). A room of $90 \mathrm{~m}^{3}$ total volume is assumed finished with $60 \mathrm{~m}^{2}$ of hygroscopic materials. An air change rate of $0.5 / \mathrm{h}$ and a surface mass transfer coefficient of $2.0 \cdot 10^{-8} \mathrm{~s} / \mathrm{m}$ is assumed.

Three moisture production regimes are considered:

- a long regime where $300 \mathrm{~g} / \mathrm{h}$ is produced between 0 and $8 \mathrm{am}$, and $0 \mathrm{~g} / \mathrm{h}$ at all other times.

- a short regime where $600 \mathrm{~g} / \mathrm{h}$ is produced between 0 and $1 \mathrm{am}, 6$ and $7 \mathrm{am}, 12$ am and $1 \mathrm{pm}$ and 6 and $7 \mathrm{pm}$, and $0 \mathrm{~g} / \mathrm{h}$ at all other times.

- a peak regime where $325 \mathrm{~g} / \mathrm{h}$ is produced between 6 and 8 am and 5 and $9 \mathrm{pm}$, and $25 \mathrm{~g} / \mathrm{h}$ at all other times.

Two ventilation air cases are investigated: an academic case, in which the vapour concentration of the incoming air is taken constant at $6.11 \mathrm{~g} / \mathrm{m}^{3}\left(10^{\circ} \mathrm{C} \mathrm{\&} 65 \% \mathrm{RH}\right)$, and a realistic case, in which real climatic data (data-file for Essen, Germany) are applied for the vapour concentration of the incoming air. The academic case is simulated for a 10day interval: a steady-periodic cycle is readily achieved after such interval, which is retained for analysis. The realistic case is simulated for one year plus a foregoing adjustment interval of 3 months: only the full year results are retained. The amplitudes of the interior $\mathrm{RH}$ are considered inversely representative for the interior moisture buffering effects and are defined here as: 
0 for the academic conditions: half the difference in interior $\mathrm{RH}$ levels at respectively the start and end of the moisture production interval. This implies that two amplitudes result for the peak regime, one for the 6 to $8 \mathrm{am}$, and one for the 5 to $9 \mathrm{pm}$ production event respectively;

0 for the realistic conditions: instead of the interior $\mathrm{RH}$ levels at the start and end of the moisture production intervals, running 24-h maxima and minima are respectively used. This results in hourly values of 'running amplitude': their yearly average is used as representative amplitude. In this case, all regimes result in a single amplitude;

Figure 3 illustrates the relation between the $\mathrm{MBV}_{8 \mathrm{~h}}$ and the interior $\mathrm{RH}$ amplitudes from moisture buffering simulations for the academic and realistic cases with the long, short, peak moisture production regimes. While $\mathrm{MBV}_{8 \mathrm{~h}}$ dependably characterises the interior moisture buffering for the long regime, this is not the case for the short or peak regime: the formerly observed uniqueness of the relations is lost. This can be clearly observed for $\mathrm{MBV}_{8 \mathrm{~h}}$ between 0.5 and $1.0 \mathrm{~g} /\left(\mathrm{m}^{2} . \% \mathrm{RH}\right)$. Hence, $\mathrm{MBV}_{8 \mathrm{~h}}$ can only be considered to dependably characterise the single-element MBP characterisation when the long moisture production regime is targeted. Only then do the realistic moisture production interval and the time intervals applied in the MBP characterisation agree. Generally, it must be concluded that a dependable single-element MBP characterisation requires the time intervals applied in the characterisation to correspond with the likely moisture production regime in practice. Figure 2 implies though that these practical moisture production intervals may vary: from one hour for the bathroom, over four-to-five hour for the living room and kitchen, up to eight hour for the bedroom. This variation is not recognised by any of the cyclic step-change (de)sorption measurement protocols $[19,21,22]$ and their enhancement is required.

\section{Production-interval adaptive MBP characterisation}

To correct for the above-mentioned flaw, a weighted-average MBP characterisation is proposed here as enhancement:

$$
\mathrm{MBV}^{*}=\alpha \cdot \mathrm{MBV}_{8 \mathrm{~h}}+(1-\alpha) \cdot \mathrm{MBV}_{1 \mathrm{~h}}
$$

with $\mathrm{MBV}^{*}$ the production-interval adapted $\mathrm{MBV}, \mathrm{MBV}_{\mathrm{8h} / \mathrm{h}}$ measured $\mathrm{MBV}$ values (see below) and $\alpha(-)$ is a weighting factor (see below). The MBV* is introduced here from the NT protocol, but the methodology is similarly applicable to the JIS or DIS protocol. The newly introduced $\mathrm{MBV}_{1 \mathrm{~h}}$ does not call for extra measurement effort, as it additionally results from the normal $M B V_{8 h}$ measurement. Just like $\mathrm{MBV}_{8 \mathrm{~h}}$ is derived from the accumulated moisture after eight hour at high $\mathrm{RH}, \mathrm{MBV}_{1 \mathrm{~h}}$ is derived from the accumulated moisture after just one hour at the high $\mathrm{RH}$ level within the $8 / 16 \mathrm{~h}$ measurement. Simulations indicate that this procedure yields similar $\mathrm{MBV}_{1 \mathrm{~h}}$ as would result from a focused measurement with a 1-hour high $\mathrm{RH}$ and, for example, a 2-hour low $\mathrm{RH}$ interval. The determination of $\mathrm{MBV}_{1 \mathrm{~h} / \mathrm{gh}}$ is graphically illustrated in Figure 4 for $1 \mathrm{~cm}$ and $10 \mathrm{~cm}$ gypsum plaster.

The following values are proposed for the weighting factor $\alpha$ :

o 0 hour < production interval $\leq 2$ hour: $\quad \alpha=0.0$;

o 2 hour < production interval $\leq 6$ hour: $\quad \alpha=0.5$;

o 6 hour < production interval $\leq 10$ hours: $\quad \alpha=1.0$;

When accurate information on the production regime is available, more detailed values for a may be applied. If even longer moisture production intervals are anticipated, a similar weighted-average could be derived for the JIS 24 / $24 \mathrm{~h}$ scheme. In that case, a determination of $\mathrm{MBV}_{1 \mathrm{~h}}, \mathrm{MBV}_{8 \mathrm{~h}}$ and $\mathrm{MBV}_{24 \mathrm{~h}}$, with appropriate interpolation factors, may be recommended. For the long, short and peak production regimes considered in this paper, Eq. (10) is deemed appropriate, and $\alpha$ is assumed 1,0 and 0.5 respectively. 
The resulting relations between $\mathrm{MBV}^{*}$ and the interior $\mathrm{RH}$ amplitudes are brought together in Figure 5: the comparison with Figure 3 indicates that the use of $\mathrm{MBV}^{*}$ results in far more consistent MBP - interior RH amplitude relations. The strong uniqueness of the relations depicted in Figure 5 points out that the production-interval adapted MBV* yields a dependable characterisation of single-element MBP. Observe that this is also true for the peak production regime, where the average of $\mathrm{MBV}_{8 \mathrm{~h}}$ and $M B V_{1 \mathrm{~h}}$ is used as MBP for both a 2- and a 4-hour moisture production interval.

\section{Room-enclosure MBP characterisation}

As the moisture exchange between indoor air and enclosure is determined by the contribution of the different hygroscopic elements comprised in the enclosure, the first part of this study elaborated the characterisation of a single-element MBP. To fulfil the first three criteria mentioned in the introduction (dependable assessment, direct qualitative comparison, and fast and easy characterisation), the production-interval adapted MBV* characterisation for a single element was presented. The experiment to determine the $\mathrm{MBV}^{*}$ of a cladding is easy to perform and straightforward, but its application is currently restricted to single elements.

Real rooms on the other hand are generally cladded with several finishes and may moreover comprise interior objects: furniture, decoration, carpets, drapes, books, etc. Recently Ramos and de Freitas [23] proposed to characterise a room's hygric inertia as a superposition of the MBP of the interior finishes and objects in the room:

$$
\mathrm{HIR}=\left(\sum \mathrm{A}_{\mathrm{k}} \cdot \mathrm{MBP}_{\mathrm{k}}+\sum \mathrm{MBP}_{\mathrm{I}}^{\prime}\right) / \mathrm{V}
$$

with $H I R\left(\mathrm{~kg} / \mathrm{m}^{3} / \% \mathrm{RH}\right)$ the hygric inertia per cubic meter of room, $M B P_{k}\left(\mathrm{~kg} / \mathrm{m}^{2} / \% \mathrm{RH}\right)$ and $A_{k}\left(\mathrm{~m}^{2}\right)$ the moisture buffer potential and area of finish $k, M B P^{\prime},(\mathrm{kg} / \% \mathrm{RH})$ the equivalent moisture buffer potential of object $I$ and $V\left(\mathrm{~m}^{3}\right)$ the volume of the room. Generalising Eq. (11) to a production-interval adaptive $H^{*} R^{*}$ characterisation by use of MBV*, we obtain:

$$
\operatorname{HIR}^{*}=\left(\sum \mathrm{A}_{\mathrm{k}} \cdot \mathrm{MBV}_{\mathrm{k}}^{*}+\sum M B V_{1}^{\prime *}\right) / \mathrm{V}=\alpha \cdot \mathrm{HIR}_{8 \mathrm{~h}}+(1-\alpha) \cdot \mathrm{HIR}_{\text {1h }}
$$

where $H I R_{8 h / 1 h}\left(\mathrm{~kg} / \mathrm{m}^{3} / \% \mathrm{RH}\right)$ are the long/short term inertia and $\alpha$ the weighting factor depending on the moisture production scheme concerned. While its thermal analogue is generally accepted and widely used, the validity of Eqs. (11-12) still requires verification. Therefore interior moisture buffering simulations are performed with different surface area's $\left(40 \mathrm{~m}^{2}\right.$ and $\left.100 \mathrm{~m}^{2}\right)$ of single finishes, and with combinations of different finishes (total surface area: $60 \mathrm{~m}^{2}$ ). As the former investigations of $\mathrm{MBV}^{*}$ proved the dependability for all kinds of production regimes and boundary conditions, the current numerical simulations are limited to the long moisture production scheme and the academic ventilation air condition only.

The resulting relations between $\mathrm{HIR}^{*}$ and the interior $\mathrm{RH}$ amplitude are shown in Figure 6. As for $\mathrm{MBV}^{*}$, an acceptably unique relationship between the dampening of the interior $\mathrm{RH}$-variations and the $\mathrm{HIR}^{*}$-value of the building enclosure is found. It can thus be stated that the hygric inertia of an entire room enclosure can be determined from its different contributing components. This implies that the fourth criterion, requiring that the MBP characterisation should be extendable to the level of the room enclosure, is met, and that the MBP of a room enclosure can be qualitatively assessed based on its HIR* value. The developed MBP characterisation requires simple and fast cyclic step-change (de)sorption measurements, and is applicable for homogeneous finishes as well as for multimaterial and multidimensional interior elements. 


\section{QUANTIFICATION OF INTERIOR MOISTURE BUFFERING BY ENCLOSURES}

The previous section revealed that - analogous with the thermal inertia - the hygric inertia of a building enclosure can be determined through superposition. Making use of the production-adaptive $\mathrm{MBV}^{*}$ of the different finishes and objects in the room, the proposed characterisation showed to be dependable for a wide variety of different moisture production schemes. Ultimately however, one doesn't only want to qualitatively assess the enclosure's MBP, but also aims to quantitatively assess its effect on the interior humidity variations (criterion 5 ). It will be shown in this section that the introduced $H I R^{*}$-value can equally be employed to arrive at the parameters required in the simplified EMPD and EC models, now based though on simple and fast measurements only and applicable for interior finishes and objects alike.

\section{Effective moisture penetration depth model}

The EMPD model is originally developed for moisture storage in building walls, assuming that only a thin layer near the interior surface interacts with the indoor air: the buffer storage layer. Some models solve Eq. (4) separately for all available humidity buffering finishes [e.g. 43]. In most BES-codes however, all interior elements need to be lumped into one equivalent buffer layer. The moisture properties of the layer have to be chosen such that they result in similar storage behaviour. This approach could also be applied to comprise multidimensional interior objects (furniture, drapes, books, ...) in that equivalent humidity buffer layer. However, no suitable methodology, providing guidance in this lumping process, is available.

In this section such methodology is presented, transforming the room-enclosure MBP characterisation $\mathrm{HIR}^{*}$ to an equivalent single buffer layer, thus applicable in the EMPD model. For a single homogeneous material, by describing the active layer thickness $d_{b}$ as a fraction a of the moisture penetration depth $d_{p}$ (Eq. (5)), Eq. (4) can be written as:

$$
A \cdot \frac{p_{v i}-p_{v b}}{\frac{1}{\beta_{i}}+a \cdot \sqrt{t_{p} / \pi} /(2 . b)}=A \cdot a \cdot \sqrt{t_{p} / \pi} \cdot b \frac{\partial p_{v b}}{\partial t} \quad a=\min \left(d / d_{p}, 1\right)
$$

with $b\left(\mathrm{~s}^{3 / 2} / \mathrm{m}\right)$ is the material's effusivity. Eq. (10) implies that the storage response of an element is essentially governed by the material's effusivity $b$ and the thickness adjustment factor $a$. On the other hand, the analytic solution for moisture accumulation in a finite homogeneous slab due to a step-change in environment vapour pressure [45] which is used in the MBV-characterisation procedure - is equally governed by $b$ and $a$, implying that $b$ and $a$ can be determined from the measured $M B V_{8 \mathrm{~h} / 1 \mathrm{~h}}$. Hence, $\mathrm{MBV}_{8 \mathrm{~h} / 1 \mathrm{~h}}$ can be used to quantify the moisture buffer effects via Eq. (13), not only for homogeneous finishes, but also to transform multidimensional objects into an equivalent buffer layer. Similarly, the HIR $8 \mathrm{~h} / 1 \mathrm{~h}$-values, characterising the hygric inertia of a complete building enclosure, can be used to obtain an enclosure equivalent $b_{e q}$ and $a_{e q}$ :

$$
H I R_{8 h / 1 h}=\frac{\sum A_{k} \cdot M B V_{k, 8 h / 1 h}+\sum M B V_{1,8 h / 1 h}^{\prime}}{V}=\frac{A_{\text {TOT }} \cdot M B V_{\text {eq,8h/1h }}}{V}
$$

Following [45] $M B V_{\text {eq, } 8 h / 1 h}$ can be written as:

$$
\begin{array}{r}
M B V_{\text {eq }, 8 \mathrm{~h} / \mathrm{hh}}=a_{\text {eq }} \cdot \sqrt{\frac{t_{p}}{\pi}} \cdot b_{\text {eq }} \cdot \Delta p_{\text {vi }}\left(1-\sum_{i=1}^{\infty}\left(\frac{2 \omega^{2}}{\gamma_{i}{ }^{2}\left(\omega(\omega+1)+\gamma_{i}{ }^{2}\right)} \exp \left(-\gamma_{i}{ }^{2} \tau\right)\right)\right) \\
\text { with } \omega=\frac{a_{\text {eq }} \cdot \beta}{b_{\text {eq }}} \cdot \sqrt{\frac{t_{p}}{\pi}}, \tau=\frac{\pi \cdot t}{a_{\text {eq }}^{2} \cdot t_{p}} \text { and } \gamma_{i} \text { roots of } \gamma \cdot \tan (\gamma)=\omega
\end{array}
$$


Knowing $\mathrm{HIR}_{8 \mathrm{~h}}$ and $\mathrm{HIR}_{1 \mathrm{~h}}$, the effusivity $b_{e q}$ and adjustment factor $a_{e q}$ of the equivalent single buffer layer of the complete room enclosure can be obtained from Eq. (15), with $t_{p} 24$ hours and $t 8$ hours and 1 hour respectively. Note that due to the influence of the surface film transfer coefficient, a reliable fit of $a_{e q}$ and $b_{e q}$ can only be achieved with a good assumption of the total exchange surface $A_{\text {TOT. }}$. For interior finishes, the real surface area can be taken. To transform the hygric inertia of a whole building zone to an equivalent single buffer layer, the exchange surface area should be taken close to the sum of all surface areas of finishes and other hygroscopically active interior objects in the zone. Determination of it could possibly be based on a 3D-room model as presented in [44], but the next section will show that rough estimates of the exchange surface suffice. If the effect of the surface film coefficient is negligible, fitting can be performed on $a_{\text {eq }}$ and $A_{\text {Tот. }} . b_{\text {eq }}$ instead of $a_{\text {eq }}$ and $b_{\text {eq }}$, making use of the analytic solution for a step change in surface vapour pressure [45].

\section{Effective capacitance model}

The EC model assumes the mass of moisture buffered in the hygric inertia of the room $M_{\text {buf }}(\mathrm{kg})$ in equilibrium with the room humidity and proportional to the HIR* ${ }^{*}$-value of the room enclosure. That allows to write the water vapour exchange $G_{b u f}$ of Eq. (2) as:

$$
\mathrm{G}_{\mathrm{buf}}=\frac{\partial \mathrm{M}_{\mathrm{buf}}}{\partial \mathrm{t}}=\frac{100 \cdot \mathrm{HIR} \mathrm{R}^{*} \cdot \mathrm{V}}{\mathrm{p}_{\mathrm{v}, \mathrm{sat}}} \frac{\partial \mathrm{p}_{\mathrm{vi}}}{\partial \mathrm{t}}
$$

The factor 100 appears in the equation to convert the $\mathrm{kg} / \% \mathrm{RH} / \mathrm{m}^{3}$ unit of the HIR*-value back to $\mathrm{kg} / \mathrm{m}^{3}$. Eq. (16) transforms Eq. (1) into:

$$
\left(\frac{V}{R_{v} T_{i}}+\frac{100 \cdot H I R^{*} \cdot V}{p_{v, s a t}}\right) \frac{\partial p_{v i}}{\partial t}=\left(p_{v e}-p_{v i}\right) \frac{n V}{3600 R_{v} T_{i}}+G_{v p}
$$

and the multiplication factor $M$ of Eq. (6) for a given building enclosure is now defined as:

$$
M=\left(1+\frac{100 \cdot \mathrm{HIR}^{*}}{\rho_{\mathrm{v}, \mathrm{sat}}}\right)
$$

with $\rho_{v, \text { sat }}$ the saturated interior vapour density $\left(\mathrm{kg} / \mathrm{m}^{3}\right)$. Compared with the rough estimates for the multiplication factor $M$ mentioned in some BES-code manuals [e.g. [31], or the value determined with the EMPD model (Eq. (7)), the value proposed in Eq. (15) corresponds to a reliable total enlarged moisture capacity of the building enclosure. As an example, Table 2 gives the HIR*-values and corresponding multiplication factors $M$ for a $90 \mathrm{~m}^{3}$ room $\left(\mathrm{b} \times \mid \times \mathrm{h}=5 \times 6 \times 3 \mathrm{~m}^{3}\right)$, finished and furnished with different elements. In addition to some of the seven original finishing materials also the woollen carpet and the bookshelf of Fig. 1 are used as furniture and finish in the room. As can be seen the multiplication factor varies between 1 and 22, which is far above the recommendations found in the TRNSYS-manual [31], proposing values in the range of 1 to 10 .

\section{Comparison of the results}

To illustrate the quantitative applicability of $\mathrm{HIR}^{*}$, interior moisture buffering simulations are performed based on the simplified EMPD and EC models. We limit the hygric inertia in the room to $60 \mathrm{~m}^{2}$ of finish, so the two simplified approaches can be compared to full numerical simulation of the moisture exchange with the enclosure. Two different finishes are considered: $1 \mathrm{~cm}$ wood fibre board (WFB) and $1 \mathrm{~cm}$ plywood (PW). While being academic, it is assumed that they are equally illustrative. The main properties of these finishes are gathered in Appendix 1 (Table 5). Simulations are made for a room finished with WFB and PW only, and for both materials combined. In the combined case, WFB and PW are each applied with $30 \mathrm{~m}^{2}$ surface area. 
To translate the HIR*-values to an equivalent single buffer layer in the effective moisture penetration depth model, the period $t_{p}$ has to be chosen (Eq. (15)). Like the weighting factor $\alpha$ in the $\mathrm{HIR}^{*}$-approach, the period is function of the moisture production regime. For the current study it is set 24,12 and 6 hours for respectively the long $(\alpha=1.0)$, peak $(\alpha=0.5)$ and short regime $(\alpha=0.0)$.

Figure 7 shows the results when $30 \mathrm{~m}^{2}$ of WFB are combined with $30 \mathrm{~m}^{2}$ of PW for the academic conditions. Similar results are found for other cases. As an example for the realistic conditions, Figure 8 plots the response of the room one day at the end of May. Again, similar graphs could be shown for the rooms solely finished with $60 \mathrm{~m}^{2}$ of WFB or PW. Note that, while only single finishing materials are considered here for reason of comparison, the MBV of WFB or PW could equally represent the MBV' of an interior object.

Both for the academic and realistic conditions, a close agreement is found between the fully numerical and the EMPD solution. This supports the applicability of HIR* for a reliable quantification of the equivalent single buffer capacity and permeability. For the EC model on the other hand, fair predictions of the $\mathrm{RH}$ minima and maxima are found, but it is not able to predict the exact course of the indoor $\mathrm{RH}$-variations. Such is no flaw of the developed HIR* methodology, but a well-known shortcoming of the EC model.

\section{PRActical example}

To illustrate the capability of the HIR*-approach and to stress the importance of a correct characterisation of a room enclosure's hygric inertia, the present section exemplifies the developed methodology with a practical case. We consider a small library of 14 by $15 \mathrm{~m}^{2}$, with a height of 4 meter. The library contains in total 24 book racks of 5 by 1.8 meter, lined up in twos, back to back. A plan view of the library is given in Figure 9 . One wall $\left(15 \times 4 \mathrm{~m}^{2}\right)$ is totally glazed, while the other walls are finished with $1 \mathrm{~cm}$ gypsum plaster on concrete and an acoustical ceiling is applied on the ceiling surface. The buffering materials considered and their $\mathrm{MBV}_{8 \mathrm{~h} / 1 \mathrm{~h}}$-values are collected in Table 3. A HVAC-system injects continuously preconditioned air at $20^{\circ} \mathrm{C}$ and $50 \% \mathrm{RH}$ at a rate of $0.5 \mathrm{ACH}$. The humidity response of the library enclosure is simulated for a rainy day when visitors enter the library with wet clothes. The moisture source $G_{v p}(\mathrm{~kg} / \mathrm{s})$ of Eq. (1) is written as a function of the varying number of visitors:

$$
\mathrm{G}_{\mathrm{vp}}=\mathrm{n}_{\text {visitors }} \cdot\left(\beta \cdot \mathrm{A}_{\text {visitor }} \cdot\left(\mathrm{p}_{\mathrm{v}, \text { sat }}-\mathrm{p}_{\mathrm{vi}}\right)+1.6710^{-5}\right)
$$

assuming that each visitor corresponds to an evaporation surface $A_{\text {visitor }}\left(1.7 \mathrm{~m}^{2}\right)$, complemented with a constant term to account for the average vapour production through breathing. The surface transfer coefficient is set at $2.0 \cdot 10^{-8} \mathrm{~s} / \mathrm{m}$.

Two cases are distinguished. Firstly the response of the library is calculated when only the wall and ceiling surfaces are considered as buffering elements. In the second case also the hygric buffering by the book shelves is incorporated. The weighting factor $\alpha$ to obtain the production-adaptive hygric inertia $\mathrm{HIR}^{*}$ is taken as 1 . In both cases the RHcourse inside the library is predicted with the EMPD and the EC model. In the EC model, the multiplication factor is directly derived from the HIR*-value of the library based on Eq. (18). In the EMPD model, the global hygric inertia of the library is translated to an equivalent single buffer layer. The MBV-values, effusivity and thickness adjustment factor of the equivalent single buffer layer are gathered with the HIR*-values in Table 4. To apply the EMPD model's Eq. (14-15), the total exchange surface $A_{T O T}$ has to be determined. For the first case that exchange surface is taken as the total surface area of ceiling and walls. In the second case, when also taking into account the hygric buffering by the book shelves, the front areas of the book racks is added to the total surface area of case 1 . 
Figure 10 compares the predicted $\mathrm{RH}$-courses for both cases and both models. As a reference the predicted $\mathrm{RH}$-course when no moisture buffering is taken into account is given as well. The number of visitors during the day is plotted on the right axis of the graph. The influence of the visitors entering the library with wet clothes is clearly visible on the predicted $\mathrm{RH}$-course. However, when only the walls and ceiling are taken as buffering materials, the effect is strongly overrated: the interior $\mathrm{RH}$ runs up from 50 to $75 \%$, while when also incorporating the buffering effects of the books the increase is limited to $11 \%$. Comparing the EMPD model with the EC model the same conclusions can be drawn as in the previous section: the EC model acceptably predicts the global amplitude, but is not able to simulate the exact course of the relative humidity.

Weakest point of the presented EMPD methodology is the fact that the total exchange surface has to be determined. For the first case this is straightforward, as the surface areas of walls and ceiling can be summed. When dealing with interior objects like the book racks an exact determination of $A_{T O T}$ is much more complicated. To investigate the sensitivity of the simulations to the $A_{T O T}$-value, two extra simulations of the second case are performed. First the exchange surface is limited to the area of the walls and ceiling only, neglecting the front sides of the books. Second the value is extended by adding both the back side and top areas of the books. The values for the additional simulations are also given in Table 4. The influence on the predicted response is rather small, as can be seen in Figure 11, comparing the original case with the two additional simulations. It appears that it is not needed to accurately calculate the exchange area. A rough estimate gives sufficiently reliable results, as changing the exchange surface also affects the fitted effusivity and adjustment factor of the equivalent single buffer layer (see Table 4). This is a crucial conclusion, because it makes the presented HIR*approach easily applicable for more complicated enclosures.

\section{Conclusions}

The significance of interior humidity in attaining sustainable, durable, healthy and comfortable buildings is increasingly recognised. Ideally thus, implementation and assessment of the moisture buffering by interior enclosures should form an integrated aspect of the building design. Interior humidity is strongly influenced by interior moisture buffering by the room enclosure: both experimental and numerical studies have comprehensively shown that application of hygroscopic interior elements substantially tempers the peaks in interior humidity variation. Any appraisal of interior humidities hence needs a qualitative and/or quantitative assessment of interior moisture buffering.

While the effective moisture penetration depth and effective capacitance models do allow simplified quantification, it has been argued that their reliance on the 'moisture penetration depth' concept necessitates comprehensive material properties and hampers application to multimaterial interior finishes and multidimensional interior objects, often the primary share of a room enclosure's hygric inertia. Moreover, while enabling quantification, it has been shown that the parameters required for the EMPD and EC models do not support qualitative assessment of interior moisture buffering by enclosures. On the other hand recently several protocols for the simple and fast characterisation of the moisture buffer potential of interior finishes have been proposed. The protocols based on cyclic (de)sorption measurements were shown to exhibit greatest potential but were also shown not dependable for the possible range of real moisture production regimes. Their superposition toward a room-enclosure moisture buffer potential, while presented in literature, had moreover not been corroborated yet.

In response to these flaws in the current quantitative and qualitative assessment of interior moisture buffering, this paper introduced the production-adaptive characterisation of the moisture buffer potential of interior elements and corroborated their superposition to a room-enclosure moisture buffer potential. This room-enclosure moisture buffer po- 
tential was in the end shown to support quantification via the EMPD and EC models. In short, this paper introduced a methodology for qualitative and quantitative assessments of interior moisture buffering by enclosure, based on simple and fast measurements only and applicable to both interior finishes and objects. This paper thus presented a missing link between currently available approaches for characterisation and quantification of interior moisture buffering, greatly facilitating the appraisal of interior humidity.

\section{ACKNOWLEDGEMENTS}

The results in this paper have been partially obtained within KUL OT/04/28 'Towards a reliable prediction of the moisture stress on building enclosures', funded by the K.U. Leuven. This financial support is gratefully acknowledged.

\section{APPENDIX 1: MATERIAL PROPERTIES}

Seven different building materials, at thicknesses of $1 \mathrm{~cm}$ and $10 \mathrm{~cm}$, are used as finish in this study: wood fibreboard (WFB) [37], plywood (PW) [37], gypsum plaster (GP) [38], aerated cellular concrete (ACC) [39], cellulose insulation (Cl) [39], flax insulation (FI) [39] and perlite insulation (PI) [39]. For use of the measured data in simulations, the sorption isotherms and vapour resistance factors are described by analytic functions of the form:

$$
\begin{aligned}
& \mathrm{w}=\mathrm{w}_{\text {sat }}\left(1+(-\mathrm{m} \cdot \ln (\varphi))^{\mathrm{n}}\right)^{(1-\mathrm{n}) / \mathrm{n}} \\
& \mu=\frac{1}{\mathrm{a}+\mathrm{be}^{\mathrm{c} \varphi}}
\end{aligned}
$$

with $\varphi(-)$ the $\mathrm{RH}$ and $\mathrm{w}_{\mathrm{sat}}, \mathrm{m}, \mathrm{n}$ and $\mathrm{a}, \mathrm{b}$ and $\mathrm{c}$ parameters. The analytic fit parameters are given in Table 5, with in addition the moisture capacity, vapour permeability, 1/e penetration depth for daily cycles, moisture effusivity at $50 \% \mathrm{RH}$ and $20^{\circ} \mathrm{C}$, and the MBVvalues.

\section{REFERENCES}

[1] Li Z, Chen W, Deng S, Lin Z. The characteristics of space cooling load and indoor humidity control for residences in the subtropics. Building and Environment 2006; 41:1137-1147.

[2] Pavlovas V. Demand controlled ventilation: A case study for existing Swedish multifamily buildings. Energy and buildings 2004; 26:1029 -1034.

[3] Pasanen A-L, Kasanen J-K, Rautiala S, Ikäheimo M, Rantamäki J, Kääriäinen H, Kalliokoski P. Fungal growth and survival in building materials under fluctuating moisture and temperature conditions. International Biodeterioration \& Biodegradation 2000; 46:117-127.

[4] Sedlbauer K. Prediction of mould growth by hygrothermal calculation. Journal of Thermal Envelope and Building Science 2002; 25(4):321-336.

[5] Haverinen-Shaughnessy U, Pekkanen J, Hyvärinen A, Nevalainen A, Putus T, Korppi M, Moschandreas D. Children's homes - determinants of moisture damage and asthma in Finnish residences. Indoor Air 2006; 16(3):248-255.

[6] Mudarri D, Fisk WJ. Public health and economic impact of dampness and mold. Indoor Air 2007; 17(3):226-235.

[7] Fang L, Clausen G, Fanger PO. Impact of temperature and humidity on the perception of indoor air quality. Indoor Air 1998; 8(2):80-90.

[8] Toftum J, Fanger PO. Air humidity requirements for human comfort, ASHRAE Transactions 1999; 105(2):641-647. 
[9] Padfield T. The role of absorbent building materials in moderating changes of relative humidity. Ph.D. thesis, Technical University of Denmark, Copenhagen, Denmark 1998.

[10] Simonson CJ, Salonvaara M, Ojanen T. Heat and mass transfer between indoor air and a permeable and hygroscopic building envelope : part 1 - Field measurements. Journal of Thermal Envelope and Building Science 2004; 28(1):63-101.

[11] Svennberg K, Hedegaard L, Rode C. Moisture buffer performance of a fully furnished room. Proceedings of the $9^{\text {th }}$ International Conference on Performance of the Exterior Envelopes of Buildings, Clearwater Beach, Florida, USA, December 2-7 2007.

[12] Kurnitski J, Kalamees T, Palonen J, Eskola L, Seppänen O. Potential effects of permeable and hygroscopic lightweight structures on thermal comfort and perceived IAQ in a cold climate. Indoor Air 2007; 17:37-49.

[13] Rode C, Mendes N, Grau K. Evaluation of moisture buffer effects by performing whole-building simulations. ASHRAE Transactions 2004; 110 (2):783-794.

[14] Holm AH, Kunzel HM, Sedlbauer K. Predicting indoor temperature and humidity conditions including hygrothermal interactions with the building envelope, ASHRAE Transactions 2004; 110 (2):820-826.

[15] Simonson CJ, Salonvaara M, Ojanen T. Heat and mass transfer between indoor air and a permeable and hygroscopic building envelope : part 2 - Verification and numerical studies. Journal of Thermal Envelope and Building Science 2004; 28(2):161-185.

[16] Hameury S. Moisture buffering capacity of heavy timber structures directly exposed to an indoor climate: a numerical study. Building and Environment 2005; 40:1400-1412.

[17] Simonson CJ, Ojanen T, Salonvaara M. Moisture performance of an airtight, vapor-permeable building envelope in a cold climate. Journal of Thermal Envelope and Building Science 2005; 28(3):205-226.

[18] Osanyintola OF, Simonson CJ. Moisture buffering capacity of hygroscopic building materials: experimental facilities and energy impact. Energy and Buildings 2006; 38:1270-1282.

[19] Rode C, Peuhkuri R, Time B, Svennberg K, Ojanen T. Moisture buffer value of building materials. Journal of ASTM International 2007; 4(5).

[20] Delgado JMPQ, Ramos NMM, De Freitas VM. Can moisture buffer performance be estimated from sorption kinetics ? Journal of Building Physics 2006; 29(4):281-299.

[21] JIS A 1470-1. Test method of adsorption/desorption efficiency for building materials to regulate an indoor humidity - part 1: response method of humidity, 2002.

[22] ISO/DIS 24353. Hygrothermal performance of building materials and products determination of moisture adsorption/desorption properties in response to humidity variation, 2006.

[23] Ramos NM, de Freitas VP. Evaluation strategy of finishing materials contribution to the hygroscopic inertia of a room. Research in Building Physics and Building Engineering, Concordia University, Montreal, Canada 2006: 543-548.

[24] Simonson CJ, Salonvaara J, Ojanen T. Improving indoor climate and comfort with wooden structures. VTT Publication 431. VTT Technical Research Centre of Finland, 2001.

[25] Künzel H. Zirkelbach D, Sedlbauer K. Predicting indoor temperature and humidity conditions including hygrothermal interactions with the building envelope. Proceedings of $1^{\text {st }}$ linternational Conference on Sustainable Energy and Green Architecture, Bangkok, 2003. 
[26] Rode C, Salonvaara M, Ojanen T, Simonson C, Grau K. Integrated hygrothermal analysis of ecological building. Proceedings of $2^{\text {nd }}$ International Building Physics Conference, K.U.Leuven. 2003.

[27] Steeman HJ, T'Joen C, Willockx A, De Paepe M, Janssens A. CFD modelling of HAM transport in buildings: boundary conditions. Research in Building Physics and Building Engineering, Concordia University, Montreal, Canada 2006: 535542.

[28] Kerestecioglu A, Swami M, Kamel A. Theoretical and computational investigation of simultaneous heat and moisture transfer in buildings: effective penetration depth theory. ASHREA Winter meeting, Atlanta GA, 1989.

[29] Cunningham MJ. The building volume with hygroscopic materials - an analytic study of a classical building physics problem. Building and Environment 2003; 38:329-337.

[30] Stehno V. Praktische Berechnung der instationären Luftzustandsänderungen in Aufenthaltsräumen zur Beurteilung der Feuchtigkeitsbelastung der raumbegrenzenden Bauteile. Bauphysik, 1982; 4: 128-134.

[31] TRNSYS 16, a TRaNsient SYstem Simulation program, User Guide Version 16.1. Madison: Solar Energy Lab, University of Wisconsin-Madison, 2006.

[32] Vereecken $\mathrm{E}$. How important are interior finishing materials to reduce relative humidity variations in indoor spaces. Master Thesis (in Dutch), K.U.Leuven, Belgium, 2008.

[33] Roels S, Janssen H. A comparison of the Nordtest and Japanese test methods for the moisture buffering performance of building materials. Journal of Building Physics 2006; 30(2):137-161.

[34] Janssen H, Roels S. 2008. The dependable characterisation of the moisture buffer potential of interior claddings. Proceedings of the "Nordic Symposium on Building Physics 2008", Copenhagen, Denmark, June 16-18 2008.

[35] Belgian Building Research Institute. Moisture problems in roofs - Impact of the actual boundary conditions and construction types in Belgium (in Dutch), Final report CC CIF - 966, 2004.

[36] ISO 13788. Hygrothermal performance of building components and building elements - Internal surface temperature to avoid critical surface humidity and interstitial condensation - Calculation method, 2001.

[37] Kumaran, M.K. IEA- Annex 24: Heat, air and moisture transfer in insulated envelope parts. Final report, volume 3. Task 3: Material properties. Acco Leuven, Belgium, 2004.

[38] Goossens, E. Moisture transfer properties of coated gypsum. PhD-thesis, Technical University Eindhoven, Eindhoven, The Netherlands, 2003.

[39] Peuhkuri, R. Moisture dynamics in building envelopes. PhD-thesis, Technical University of Denmark, Copenhagen, Denmark, 2003.

[40] Janssen $\mathrm{H}$, Blocken B, Carmeliet J. Conservative modelling of the moisture and heat transfer in building components under atmospheric excitation. International Journal for Heat and Mass Transfer 2007; 50:1128-1140.

[41] Talukdar P, Osanyintola O F, Olutimayin O S, Simonson CJ. An experimental data set for benchmarking 1-D, transient heat and moisture transfer models of hygroscopic building materials. Part II: Experimental, numerical and analytical data. International Journal of Heat and Mass Transfer 2007; 50: 4915-4926.

[42] Lengsfeld K, Holm A. Development and validation of the hygrothermal indoor climate simulation software WUFI@-Plus (in German). Bauphysik 2007; 29: 178186.

[43] Energyplus, 2005. 
[44] Nielsen A. 3D room models for moisture balance calculations. Proceedings of the 5th Symposium on Building Physics in the Nordic Countries, Chalmers University of Technology, 1999: 645-652.

[45] Carslaw HS, Jaeger JC. Conduction of heat in solids (second edition). At the Claredon Press, Oxford, United Kingdom, 1990. 


\section{TABLE CAPTIONS}

1. Synthesis of the different cyclic (de)sorption MBP characterisation protocols.

2. HIR-values and corresponding multiplication factors $M$ applicable in the effective capacitance model for a room of $90 \mathrm{~m}^{2}$, finished and furnished with different materials.

3. Applied areas (lengths) and MBV-values of the hygric buffering elements in the practical example of the library.

4. $H I R^{*}$-values of the library and the corresponding equivalent effusivity and thickness adjustment factor for case 1 (taking into account only walls and ceiling) and case 2 (considering walls, ceiling and book shelves). For the last case also the values are given when considering a different exchange surface.

5. Analytic fit and material parameters for the seven materials. 
TABLE 1

\begin{tabular}{|c|c|c|c|c|}
\hline & $\begin{array}{c}\text { RH levels } \\
\text { high / low (\%) }\end{array}$ & $\begin{array}{l}\text { time intervals } \\
\text { high / low (h) }\end{array}$ & $\begin{array}{l}\text { surface transfer } \\
\text { coefficient }(\mathrm{s} / \mathrm{m})\end{array}$ & $\begin{array}{c}\text { sample thick- } \\
\text { ness }\end{array}$ \\
\hline \multirow{3}{*}{ JIS A 1470-1 } & $53 / 33$ & & & \multirow{3}{*}{$\begin{array}{l}\text { as applied } \\
\text { in practice }\end{array}$} \\
\hline & $75 / 53$ & 24 / 24 & $2.1 \cdot 10^{-8}$ & \\
\hline & $93 / 75$ & & & \\
\hline \multirow{3}{*}{ DIS 24353} & $53 / 33$ & & & \multirow{3}{*}{$\begin{array}{l}\text { as applied } \\
\text { in practice }\end{array}$} \\
\hline & $75 / 53$ & $12 / 12$ & $2.1 \cdot 10^{-8}$ & \\
\hline & $93 / 75$ & & & \\
\hline Nordtest & $75 / 33$ & $8 / 16$ & sufficiently high & sufficiently thick \\
\hline
\end{tabular}

TABLE 2

\begin{tabular}{|c|c|c|c|c|c|}
\hline \multirow[b]{2}{*}{ Interior buffering elements } & \multicolumn{2}{|c|}{$\operatorname{HIR}\left(\mathrm{g} / \mathrm{m}^{3} / \% \mathrm{RH}\right)$} & \multicolumn{3}{|c|}{ M (-) } \\
\hline & $\mathrm{HIR}_{1 \mathrm{~h}}$ & $\mathrm{HIR}_{8 \mathrm{~h}}$ & $\alpha=0$ & $\alpha=0.5$ & $\alpha=1.0$ \\
\hline 0. none & 0 & 0 & 1 & 1 & 1 \\
\hline 1. walls in AAC & & & & & \\
\hline $\begin{array}{l}\text { total surface area: } 66 \mathrm{~m}^{2} \\
\text { 2. idem as } 1 .+ \text { gypsum plaster at ceiling }\end{array}$ & 0.198 & 0.594 & 2.15 & 3.29 & 4.44 \\
\hline $\begin{array}{l}1 \mathrm{~cm} \text { gypsum plaster applied at } 30 \mathrm{~m}^{2} \\
\text { 3. idem as } 1 .+ \text { acoustical ceiling }\end{array}$ & 0.291 & 0.737 & 2.69 & 3.98 & 5.27 \\
\hline $\begin{array}{l}3 \mathrm{~cm} \text { wood fibre board applied at } 30 \mathrm{~m}^{2} \\
\text { 4. only woollen carpet }\end{array}$ & 0.379 & 0.932 & 3.19 & 4.80 & 6.40 \\
\hline $\begin{array}{l}\text { applied at floor }\left(30 \mathrm{~m}^{2}\right) \\
\text { 5. only book shelf }\end{array}$ & 0.420 & 1.267 & 3.43 & 5.88 & 8.34 \\
\hline $\begin{array}{l}\text { one wall, in total } 50 \mathrm{~m} \text { book shelf } \\
\text { 6. combining } 3 \text { and } 4\end{array}$ & 0.397 & 1.359 & 3.30 & 6.09 & 8.87 \\
\hline $\begin{array}{l}\text { walls in AAC, acoustical ceiling, woollen carpet } \\
\text { 7. combining } 3,4 \text { and } 5\end{array}$ & 0.799 & 2.199 & 5.63 & 9.68 & 13.74 \\
\hline idem as $6 .+$ wooden book shelf & 1.196 & 3.558 & 7.93 & 14.77 & 21.61 \\
\hline
\end{tabular}

TABLE 3

\begin{tabular}{lccc}
\hline buffering element & $\begin{array}{c}\text { Area }\left(\mathrm{m}^{2}\right) \text { or } \\
\text { length }(\mathrm{m})\end{array}$ & $\begin{array}{c}\mathrm{MBV}^{()}{ }_{8 \mathrm{~h}} \\
\left(\mathrm{~kg} / \mathrm{m}^{(2)} / \% \mathrm{RH}\right)\end{array}$ & $\begin{array}{c}\mathrm{MBV}^{(()}{ }_{1 \mathrm{~h}} \\
\left(\mathrm{~kg} / \mathrm{m}^{(2)} / \% \mathrm{RH}\right)\end{array}$ \\
\hline $\begin{array}{l}\text { acoustical ceiling } \\
3 \mathrm{~cm} \text { wood fibre board } \\
\begin{array}{l}\text { walls } \\
1 \mathrm{~cm} \text { gypsum plaster }\end{array}\end{array}$ & 210 & 1.85 & 0.52 \\
$\begin{array}{l}\text { book racks } \\
24 \text { racks of } 5 \times 1.8 \mathrm{~m}^{2} \text {, each with 6 shelves }\end{array}$ & 172 & 0.43 & 0.28 \\
\hline
\end{tabular}




\begin{tabular}{lcc|cc}
\hline & Case 1 & Case 2 & Case 2' & Case 2" \\
\hline $\mathrm{HIR}_{1 \mathrm{~h}}\left(\mathrm{~g} / \mathrm{m}^{3} / \% R H\right)$ & 0.187 & 0.800 & 0.800 & 0.800 \\
$\mathrm{HIR}_{8 \mathrm{~h}}\left(\mathrm{~g} / \mathrm{m}^{3} / \% R H\right)$ & 0.551 & 2.647 & 2.647 & 2.647 \\
$\mathrm{HIR}^{*}\left(\mathrm{~g} / \mathrm{m}^{3} / \% R \mathrm{H}\right)$ & 0.551 & 2.647 & 2.647 & 2.647 \\
$\mathrm{M}(-)$ & 4.19 & 16.33 & 16.33 & 16.33 \\
$\mathrm{~A}_{\text {TOT }}\left(\mathrm{m}^{2}\right)$ & 382 & 598 & 382 & 778 \\
$\mathrm{MBV}_{\text {eq, }, \mathrm{h}}\left(\mathrm{g} / \mathrm{m}^{2} / \% \mathrm{RH}\right)$ & 0.41 & 1.12 & 1.76 & 0.86 \\
$\mathrm{MBV}_{\text {eq, }, \mathrm{h}}\left(\mathrm{g} / \mathrm{m}^{2} / \% R H\right)$ & 1.21 & 3.72 & 5.82 & 2.86 \\
$\mathrm{~b}_{\text {eq }}$ & $3.28 \mathrm{e}^{-7}$ & $1.92 \mathrm{e}^{-6}$ & $1.22 \mathrm{e}^{-5}$ & $1.02 \mathrm{e}^{-6}$ \\
$\mathrm{a}_{\text {eq }}$ & 1.13 & 0.54 & 0.14 & 0.82 \\
\hline
\end{tabular}

TABLE 5

\begin{tabular}{|c|c|c|c|c|c|c|c|}
\hline & WFB & PW & GP & AAC & $\mathrm{Cl}$ & $\mathrm{FI}$ & $\mathrm{PI}$ \\
\hline \multicolumn{8}{|c|}{ Sorption isotherm $\left(\mathrm{kg} / \mathrm{m}^{3}\right)$} \\
\hline $\mathrm{W}_{\text {sat }}$ & 150.0 & 200.0 & 30.4 & 258.0 & 23.5 & 370.0 & 19.8 \\
\hline $\mathrm{m}$ & 91.4 & 80.6 & 69.5 & $2.1 \cdot 10^{5}$ & 22.7 & 627.7 & 752.4 \\
\hline $\mathrm{n}$ & 1.416 & 1.337 & 1.800 & 1.317 & 1.576 & 1.950 & 1.848 \\
\hline \multicolumn{8}{|c|}{ Vapour resistance factor (-) } \\
\hline$a$ & $7.5 \cdot 10^{-2}$ & $5.0 \cdot 10^{-3}$ & $2.4 \cdot 10^{-1}$ & $1.0 \cdot 10^{-1}$ & $5.7 \cdot 10^{-1}$ & $7.7 \cdot 10^{-1}$ & $5.3 \cdot 10^{-1}$ \\
\hline $\mathrm{b}$ & $2.2 \cdot 10^{-3}$ & $3.4 \cdot 10^{-6}$ & - & $1.5 \cdot 10^{-4}$ & - & - & - \\
\hline $\mathrm{C}$ & 5.00 & 10.8 & - & 5.15 & - & - & - \\
\hline \multicolumn{8}{|c|}{ moisture capacity $\left(10^{-3} \mathrm{~kg} /\left(\mathrm{m}^{3} \cdot \mathrm{Pa}\right)\right)$} \\
\hline & 13.7 & 21.4 & 1.36 & 2.34 & 3.37 & 1.37 & 0.10 \\
\hline \multicolumn{8}{|c|}{ vapour permeability $\left(10^{-11} \mathrm{~kg} /(\mathrm{m} \cdot \mathrm{s} \cdot \mathrm{Pa})\right)$} \\
\hline & 0.63 & 0.12 & 3.04 & 1.52 & 2.99 & 5.47 & 16.4 \\
\hline \multicolumn{8}{|c|}{ 1/e penetration depth $\left(10^{-2} \mathrm{~m}\right)$} \\
\hline & 0.63 & 0.12 & 3.04 & 1.52 & 2.99 & 5.47 & 16.44 \\
\hline \multicolumn{8}{|c|}{ moisture effusivity $\left(10^{-7} \mathrm{~kg} /\left(\mathrm{m}^{2} \cdot \mathrm{s}^{0.5} \cdot \mathrm{Pa}\right)\right)$} \\
\hline & 5.19 & 1.54 & 2.49 & 2.15 & 6.06 & 4.51 & 1.03 \\
\hline \multicolumn{8}{|c|}{$\mathrm{MBV}_{8 \mathrm{~h}}$ for $1 \mathrm{~cm}$ thickness $\left(\mathrm{g} / \mathrm{m}^{2} / \% \mathrm{RH}\right)$} \\
\hline & 1.917 & 0.689 & 0.434 & 0.614 & 0.978 & 0.462 & 0.034 \\
\hline \multicolumn{8}{|c|}{$\mathrm{MBV}_{1 \mathrm{~h}}$ for $1 \mathrm{~cm}$ thickness $\left(\mathrm{g} / \mathrm{m}^{2} / \% \mathrm{RH}\right)$} \\
\hline & 0.532 & 0.226 & 0.276 & 0.282 & 0.540 & 0.340 & 0.034 \\
\hline \multicolumn{8}{|c|}{$\mathrm{MBV}_{8 \mathrm{~h}}$ for $10 \mathrm{~cm}$ thickness $\left(\mathrm{g} / \mathrm{m}^{2} / \% \mathrm{RH}\right)$} \\
\hline & 1.859 & 0.690 & 0.943 & 0.812 & 2.008 & 1.639 & 0.309 \\
\hline \multicolumn{8}{|c|}{$\mathrm{MBV}_{1 \mathrm{~h}}$ for $10 \mathrm{~cm}$ thickness $\left(\mathrm{g} / \mathrm{m}^{2} / \% \mathrm{RH}\right)$} \\
\hline & 0.524 & 0.224 & 0.303 & 0.270 & 0.567 & 0.471 & 0.146 \\
\hline
\end{tabular}




\section{FIGURE CAPTIONS}

1. $M B V^{(\varsigma)}$ characterisation of woollen carpet, of cork board and of a one meter long wooden book shelf with books.

2. Time evolution of the measured relative humidity in the different rooms of a social dwelling in Nieuwpoort, Belgium, from February 12 (12 am) until February 152004 (12 am) [35].

3. Relations between $\mathrm{MBV}_{8 \mathrm{~h}}$ and interior $\mathrm{RH}$ amplitude from moisture buffering simulations under long, short, peak moisture production regime, under academic conditions (top), and under realistic conditions (bottom).

4. Determination of $M B V_{1 \mathrm{~h} / 8 \mathrm{~h}}$ for $1 \mathrm{~cm}$ and $10 \mathrm{~cm}$ gypsum plaster. $\mathrm{RH}$ levels $75 /$ $33 \% \mathrm{RH}$, surface mass transfer coefficient $2.0 \cdot 10^{-8} \mathrm{~m} / \mathrm{s}$, time intervals $8 / 16 \mathrm{~h}$.

5. Interior $\mathrm{RH}$ amplitude from moisture buffering simulations under academic (top) and realistic (bottom) conditions and long, short, peak production regime in function of $\mathrm{MBV}^{*}$ for the 15 elements considered.

6. Relation between $\mathrm{HIR}^{*}$ and interior $\mathrm{RH}$ amplitude from moisture buffering simulations for the original cases, for cases with different surface areas and for cases with combinations of claddings.

7. Comparison of the interior $\mathrm{RH}$-courses predicted with full numerical (full black line), effective moisture penetration depth (full grey line) and effective capacitance model (dashed grey line) for the room of $90 \mathrm{~m}^{3}$, finished with $30 \mathrm{~m}^{2}$ of WFB in combination with $30 \mathrm{~m}^{2}$ of PW under academic ventilation conditions for long (top), short (middle) and peak (bottom) moisture production regimes.

8. Comparison of the interior $\mathrm{RH}$-courses predicted with full numerical (full black line), effective moisture penetration depth (full grey line) and effective capacitance model (dashed grey line) for the room of $90 \mathrm{~m}^{3}$, finished with $30 \mathrm{~m}^{2}$ of WFB in combination with $30 \mathrm{~m}^{2}$ of PW under real ventilation conditions for long (top), short (middle) and peak (bottom) moisture production regimes.

9. Plan view of the library.

10. Comparison of the interior $\mathrm{RH}$-courses predicted with the EMPD model (continuous line) and the EC model (dashed line) for case 1, taking only into account the hygric buffering of walls and ceiling and case 2, adding the book shelves as interior buffer elements. As a reference also the response of the library when only hygric buffering by the indoor air is taken into account is given.

11. Sensitivity study of the EMPD model to the exchange surface $A_{T O T}$ in Eq.(14). 
FIGURE 1

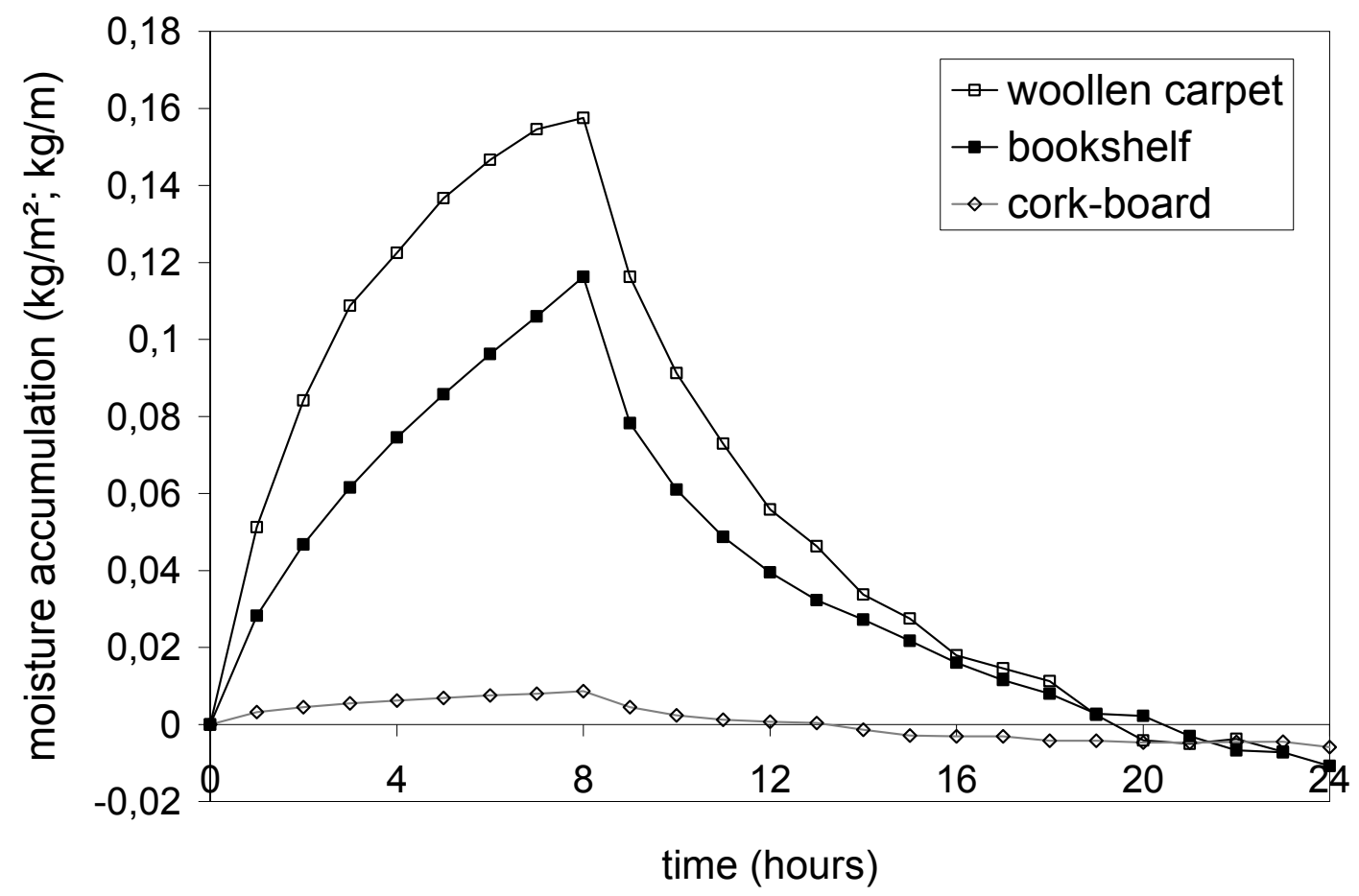

FIGURE 2

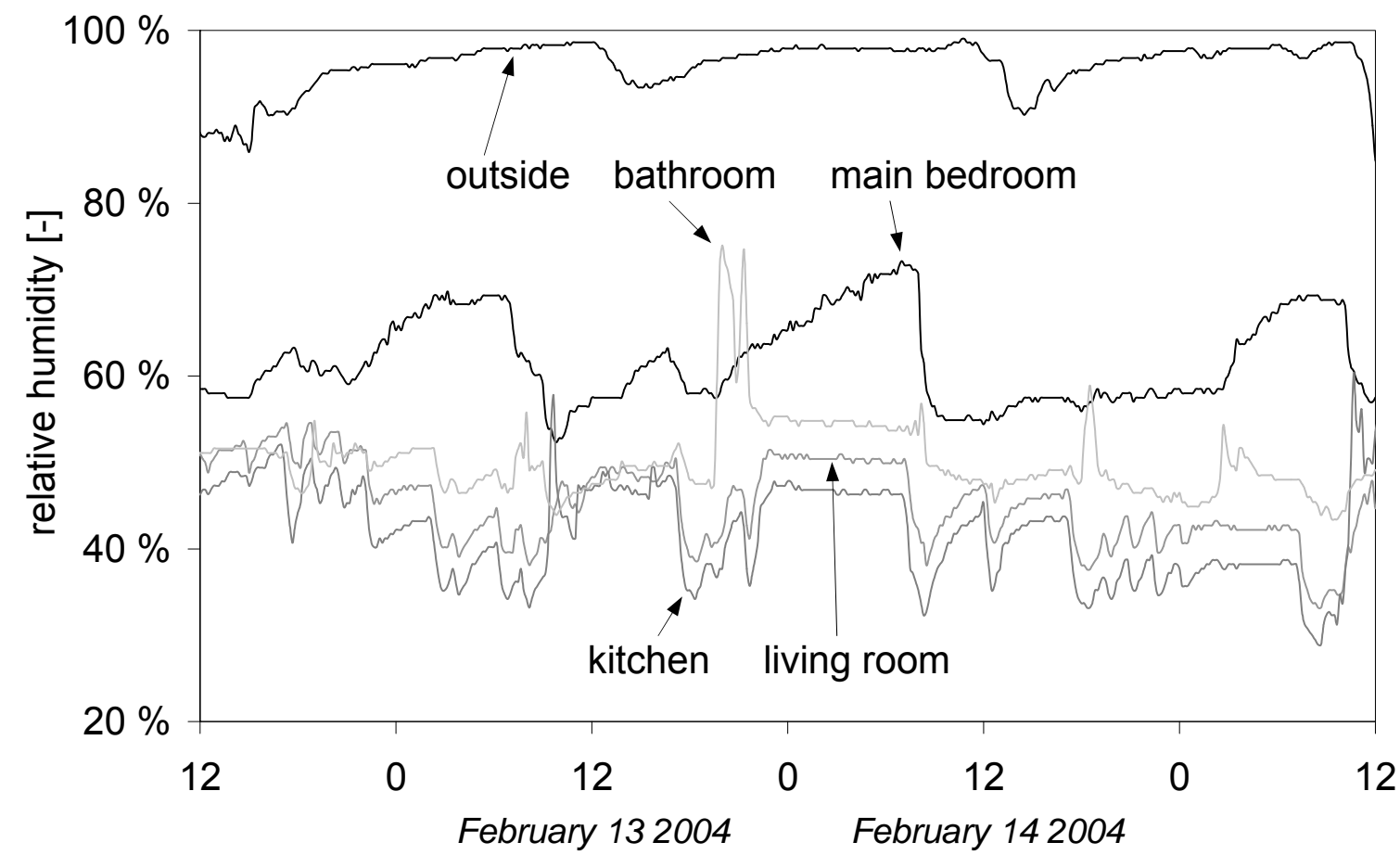


FIGURE 3
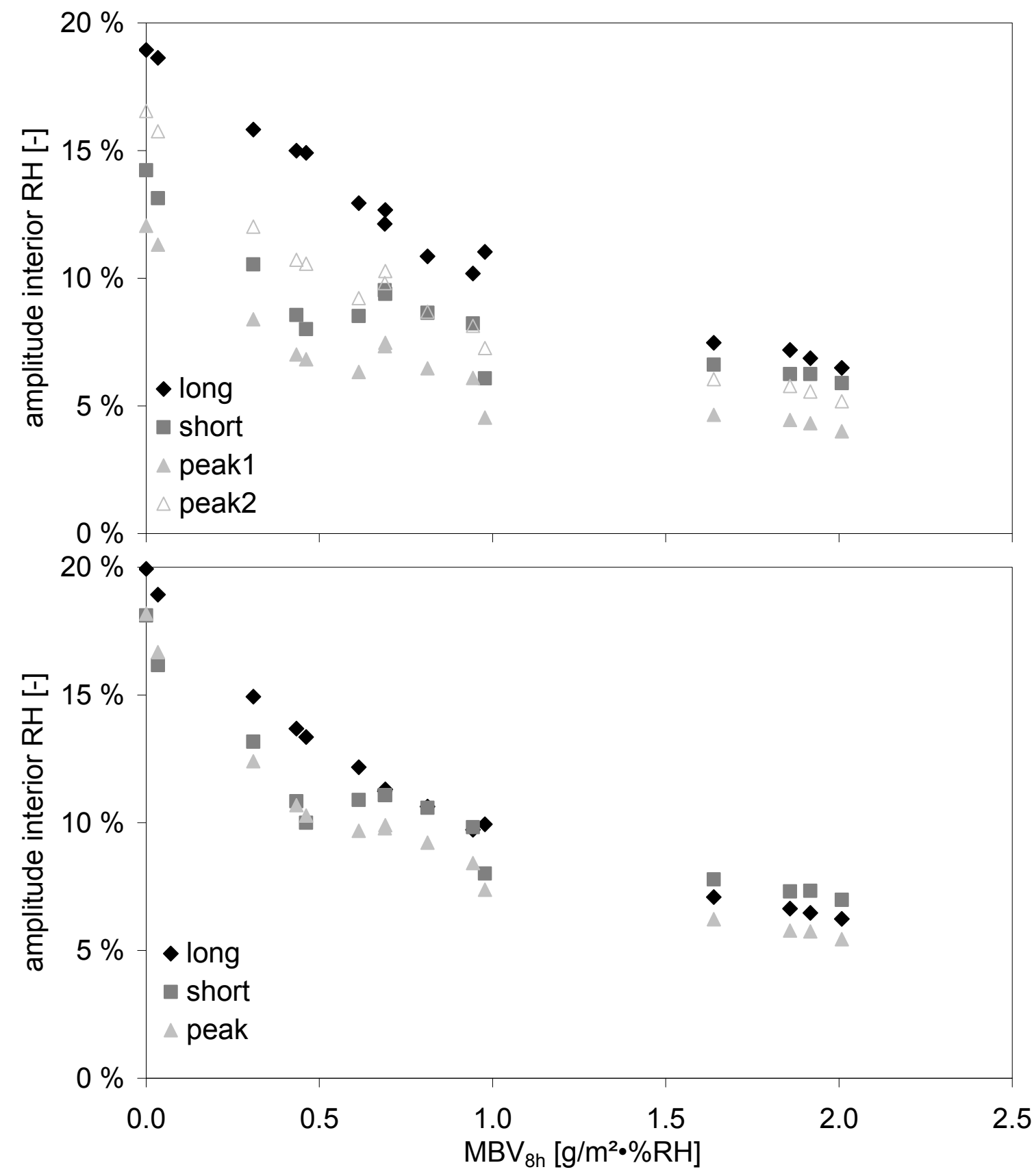
FIGURE 4

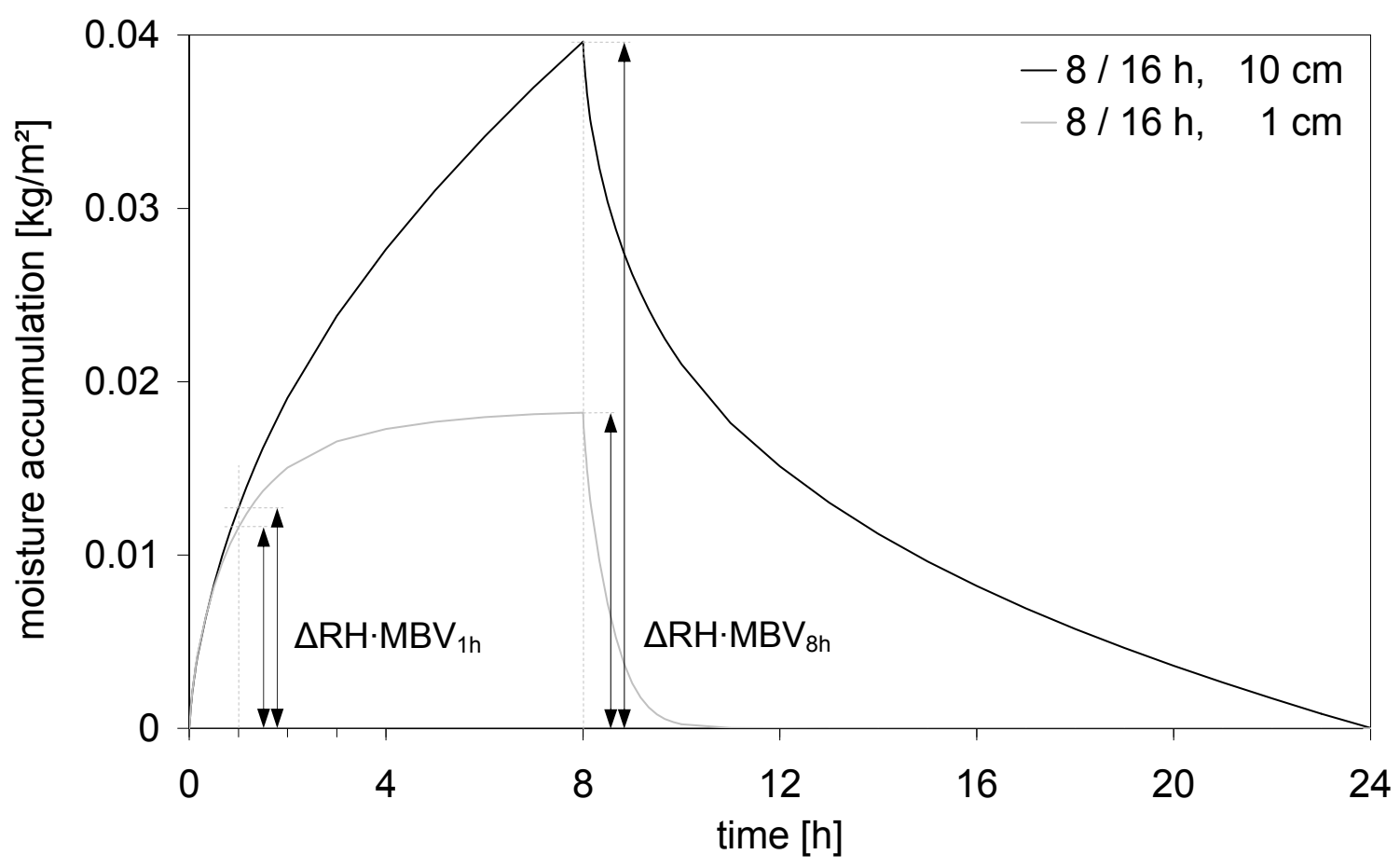


FIGURE 5
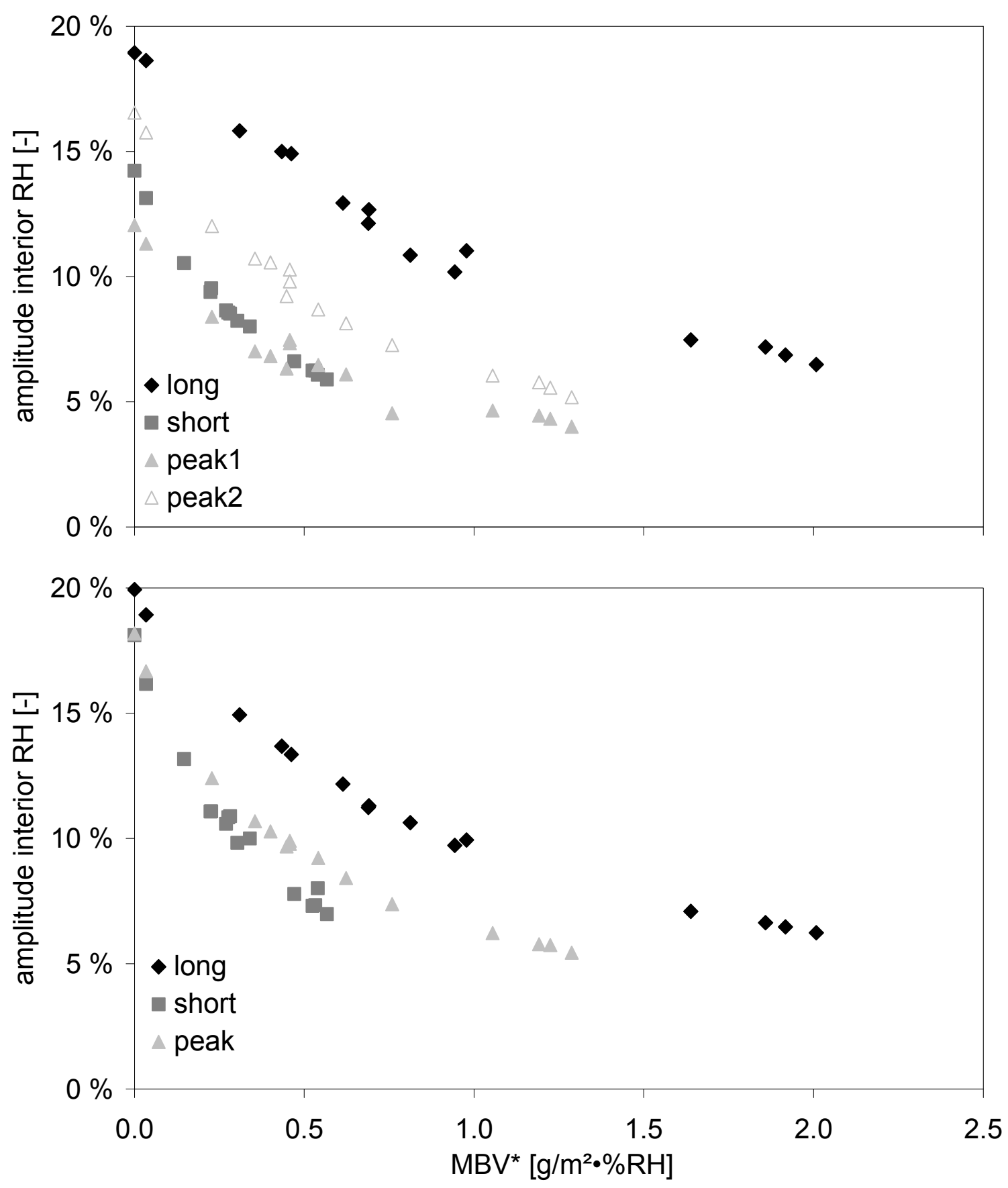
FIGURE 6

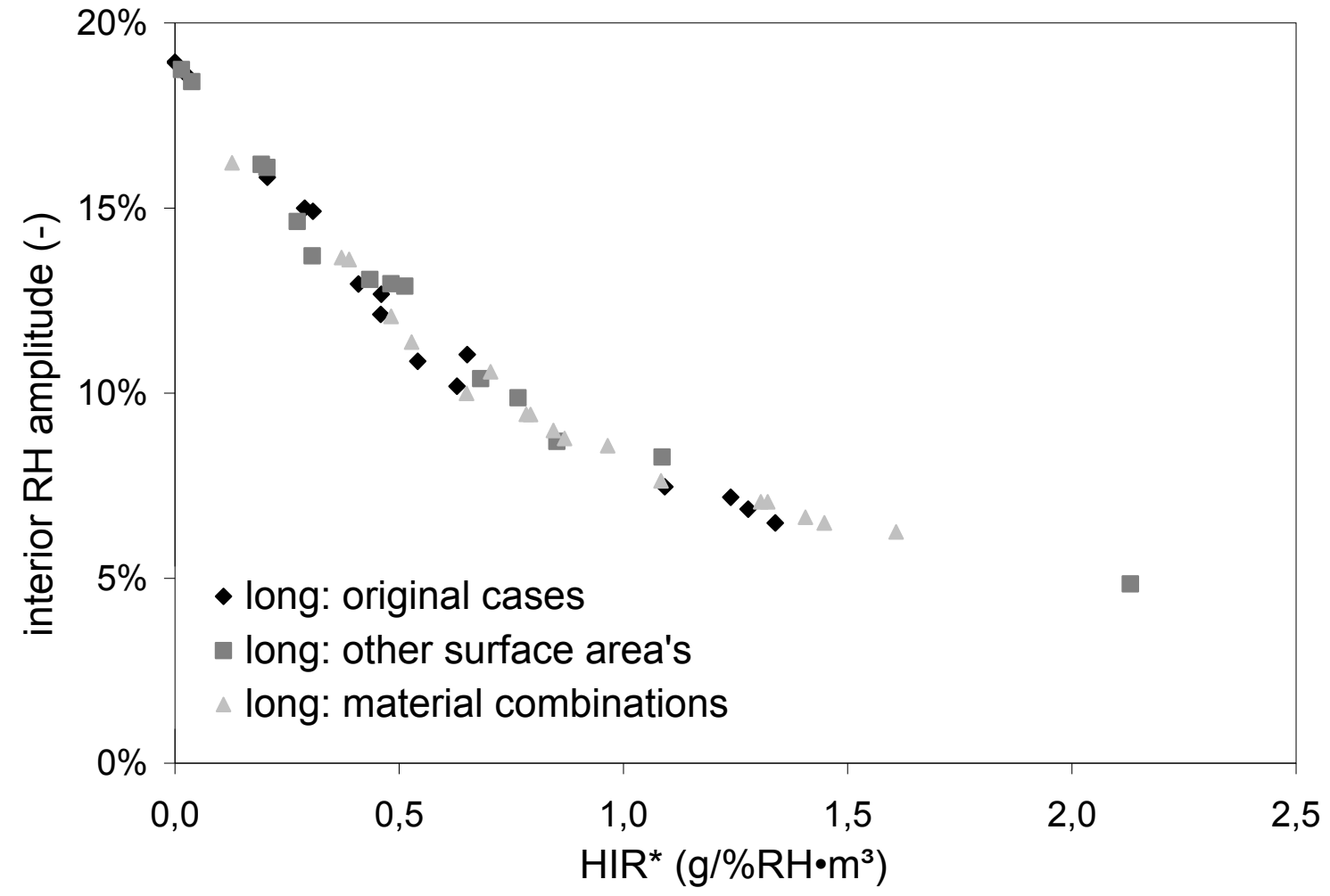


FIGURE 7
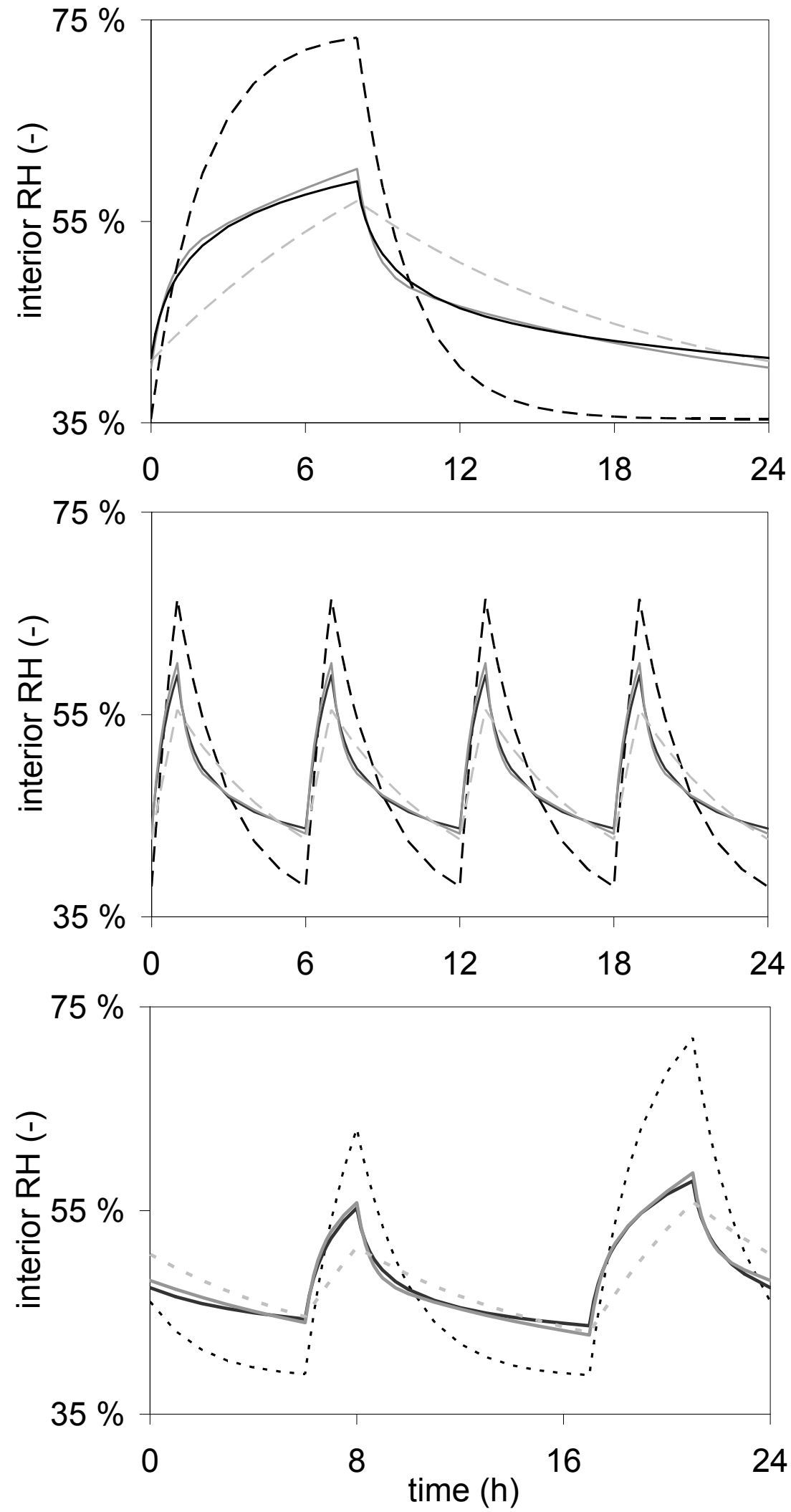
FIGURE 8
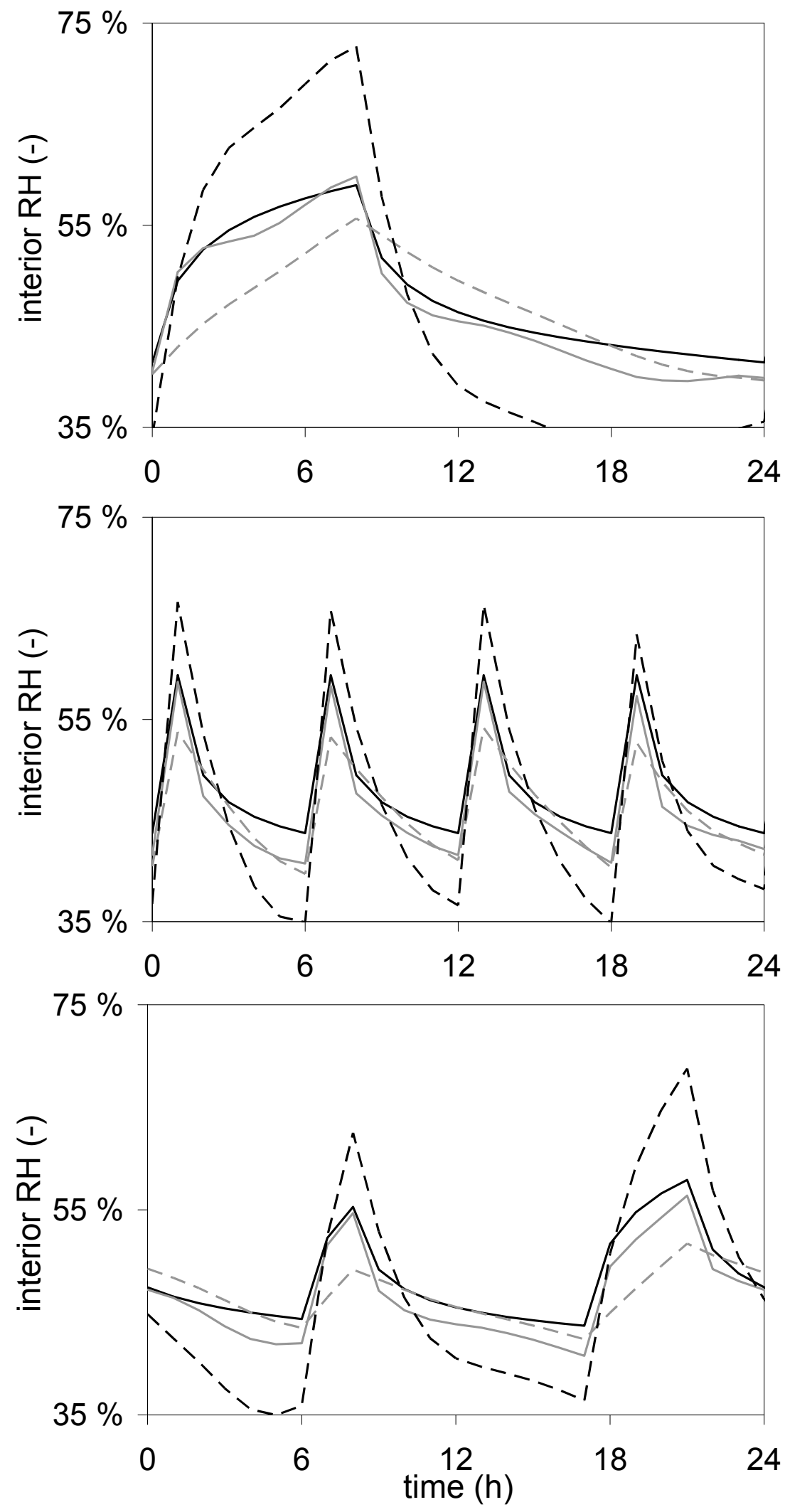
FIGURE 9

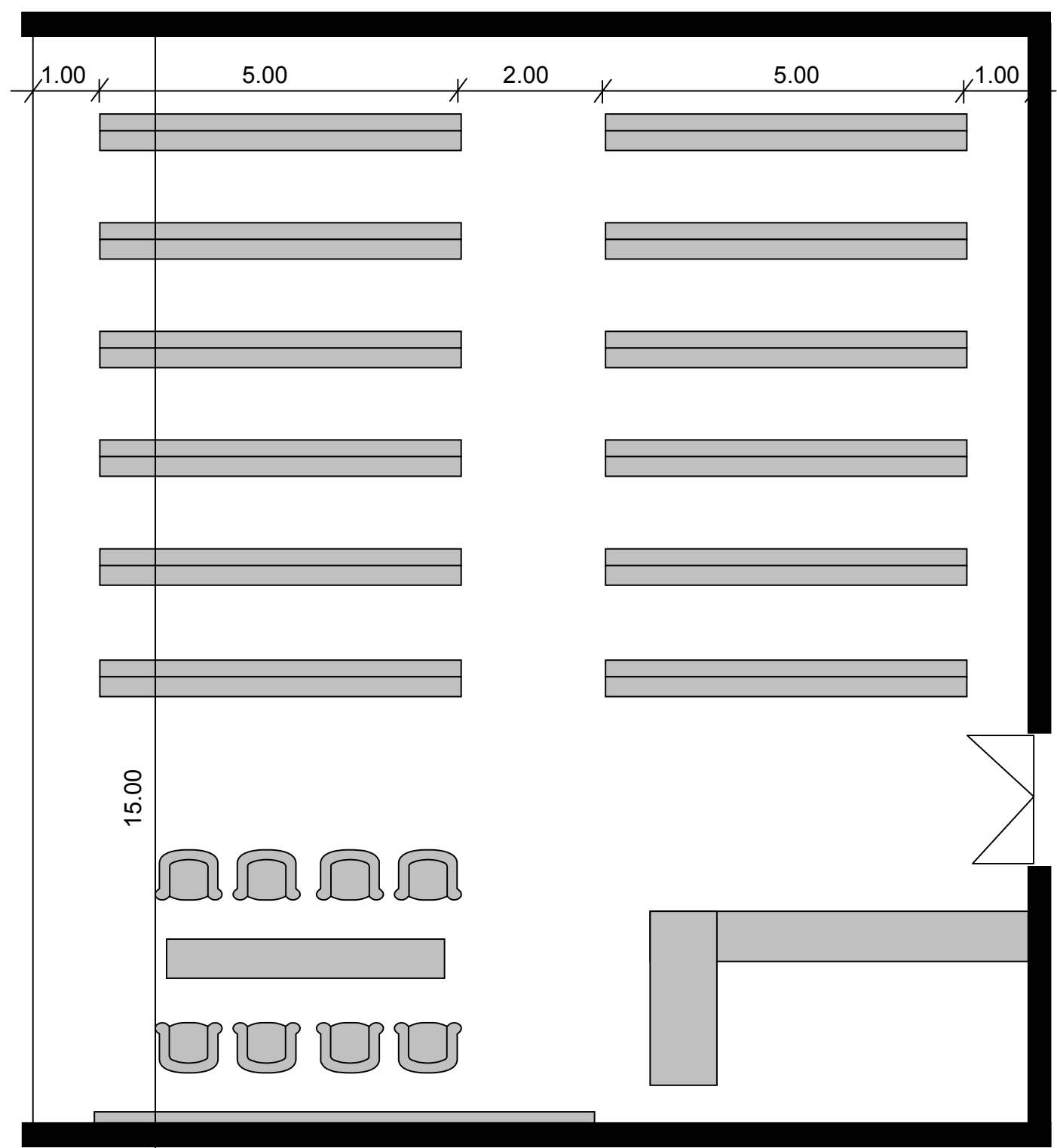


FIGURE 10

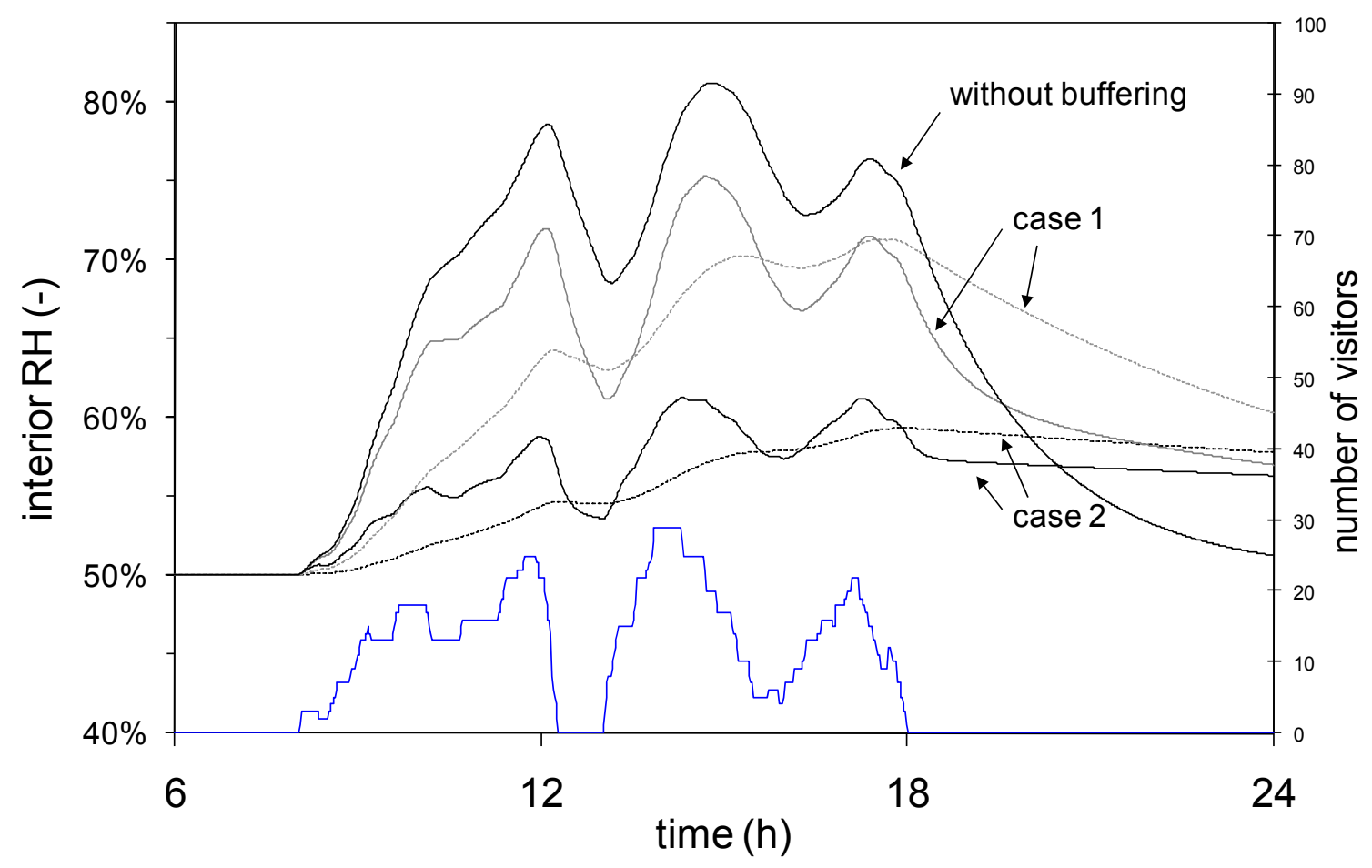

FIGURE 11

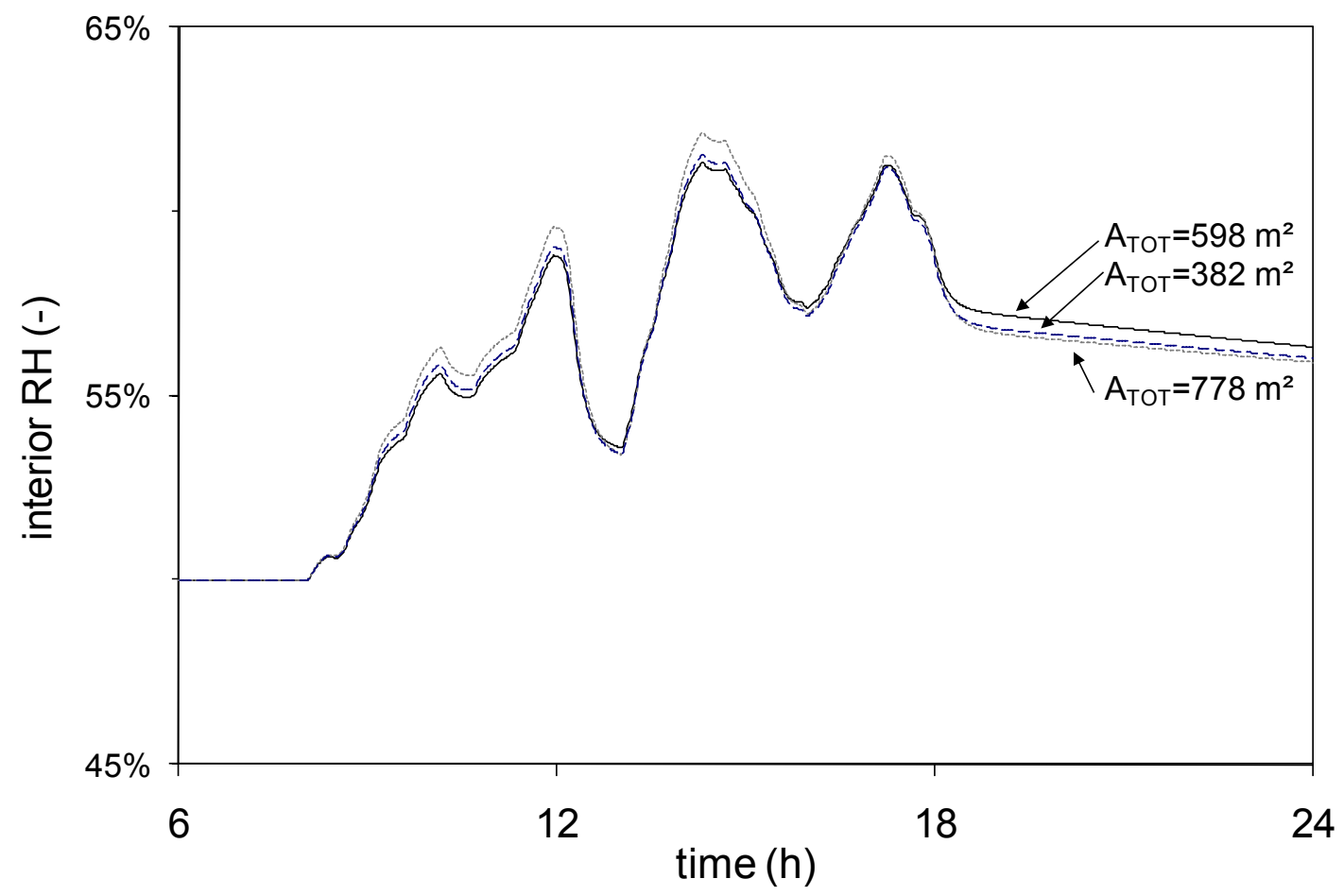

